\title{
Characterization of the phosphofructokinase gene family in rice and its expression under oxygen deficiency stress
}

\author{
Angelika Mustroph ${ }^{1}{ }^{*}$, Johanna Stock ${ }^{1}$, Natalia Hess ${ }^{1}$, Sophia Aldous ${ }^{2 \dagger}$, Anika Dreilich ${ }^{2}$ and \\ Bernhard Grimm ${ }^{2}$
}

${ }^{1}$ Department of Plant Physiology, University of Bayreuth, Bayreuth, Germany

2 Department of Plant Physiology, Institute of Biology, Humboldt-University Berlin, Berlin, Germany

\section{Edited by:}

Rens Voesenek, Utrecht University, Netherlands

Reviewed by:

Sjef Smeekens, Utrecht University, Netherlands

Shaobai Huang, The University of Western Australia, Australia

*Correspondence:

Angelika Mustroph, Department of Plant Physiology, University of

Bayreuth, Universitaetsstrasse 30 95440 Bayreuth, Germany.

e-mail: angelika.mustroph@

uni-bayreuth.de

${ }^{+}$Present address:

Sophia Aldous, Department of

Developmental and Molecular Plant

Biology, Heinrich-Heine-University

Düsseldorf, Düsseldorf, Germany.
Plants possess two types of phosphofructokinase proteins for phosphorylation of fructose6-phosphate, the ATP-dependent phosphofructokinase (PFK) and the pyrophosphate-(PPi) dependent pyrophosphate-fructose-6-phosphate-phosphotransferase (PFP). During oxygen deficiency ATP levels in rice seedlings are severely reduced, and it is hypothesized that PPi is used as an alternative energy source for the phosphorylation of fructose-6-phosphate during glycolysis. In this study, we analyzed the expression of 15 phosphofructokinaseencoding genes in roots and aerial tissues of anoxia-tolerant rice seedlings in response to anoxic stress and compared our data with transcript profiles obtained from microarray analyses. Furthermore, the intracellular localization of rice PFK proteins was determined, and the PFK and PFP isoforms were grouped in a phylogenetic tree. Two PFK and two PFP transcripts accumulated during anoxic stress, whereas mRNA levels of four PFK and three PFP genes were decreased. The total specific activity of both PFK and PFP changed only slightly during a 24-h anoxia treatment. It is assumed that expression of different isoforms and their catalytic properties differ during normoxic and anoxic conditions and contribute to balanced glycolytic activity during the low-oxygen stress. These characterizations of phosphofructokinase genes and the comparison to other plant species allowed us to suggest candidate rice genes for adaptation to anoxic stress.

Keywords: Oryza sativa, anoxia, submergence, phosphofructokinase, pyrophosphate

\section{INTRODUCTION}

The pronounced tolerance of oxygen deprivation during seed germination and vegetative development makes rice plants an interesting subject to elucidate mechanisms of response to lowoxygen stress. Oxygen deficiency results in inhibition of mitochondrial respiration, leading to NADH accumulation as well as ATP deficiency. Glycolytic production of ATP continues, when fermentative enzymes are induced and able to regenerate sufficient amounts of $\mathrm{NAD}^{+}$(reviewed in Drew, 1997; de Sousa and Sodek, 2002; Geigenberger, 2003; Gibbs and Greenway, 2003).

Plant cells frequently enhance the rate of sucrose consumption under low-oxygen stress to compensate for the low energy yield during glycolysis (2-4 mol ATP per mol glucose), in comparison to aerobic mitochondrial respiration (30-36 mol ATP per mol glucose) (Summers et al., 2000). We have shown previously that rice plants sustain a higher fermentation rate during anoxia as compared to anoxia-sensitive wheat plants, but ATP levels still drop by two-third (Mustroph et al., 2006a). The decline in cellular ATP content during low-oxygen stress will impact the glycolytic phosphorylation reactions catalyzed by hexokinases and phosphofructokinases (Bouny and Saglio, 1996). Thus, it was hypothesized that plants might use pyrophosphate (PPi) instead of ATP as an

Abbreviations: ADH, alcohol dehydrogenase; PDC, pyruvate decarboxylase; PFK, ATP-dependent phosphofructokinase; PF2K, phosphofructo-2-kinase; PFP, pyrophosphate-fructose-6-phosphate-phosphotransferase; PPi, pyrophosphate. alternative energy source for phosphorylation processes during ATP deficiency (Weiner et al., 1987; Stitt, 1998; Huang et al., 2008). $\mathrm{PPi}$ is a by-product of many biosynthetic processes like DNA and protein synthesis, and its levels are not changed during oxygen deficiency stress (Dancer and ap Rees, 1989; Mohanty et al., 1993; Mustroph et al., 2005).

Sucrose cleavage and subsequent phosphorylation of hexoses are usually catalyzed by the ATP-dependent invertase/hexokinase reaction, but can be replaced by the PPi-consuming sucrose synthase/UDP-glucose pyrophosphorylase reaction. The activation of this alternative pathway of sucrose catabolism upon oxygen deficiency stress was confirmed for several plant species, and the substitution of the ATP-dependent reactions by the UTP and PPidependent pair of enzymes is generally accepted (Springer et al., 1986; Ricard et al., 1991, 1998; Guglielminetti et al., 1995; Perata et al., 1996, 1997; Biemelt et al., 1999; Mustroph and Albrecht, 2003; Albrecht et al., 2004; Bailey-Serres and Voesenek, 2008).

The second phosphorylation step in the glycolytic pathway is the phosphorylation of fructose-6-phosphate to fructose-1,6bisphosphate via phosphofructokinase. The reaction can be performed by an ATP-dependent phosphofructokinase (PFK) or by the PPi-dependent form pyrophosphate-fructose-6-phosphatephosphotransferase (PFP). PFP consists of two different subunits (PFP-alpha, PFP-beta) that form a heterotetramer (Wong et al., 1990; Teramoto et al., 2000), whereas the subunit composition of a PFK complex is not known yet. 
The contribution of each phosphofructokinase enzyme to the phosphorylation step and their functions during different growth conditions remain unclear. While during hypoxic stress both enzyme activities are induced in wheat and maize roots (Mustroph and Albrecht, 2003), their activities do not change in roots of potato plants (Mustroph et al., 2005). Experiments with transgenic potato plants with a severe decrease in PFP activity revealed no change in aerobic (Hajirezaei et al., 1994) or anoxic metabolism (Mustroph, unpublished results). However, the PFP activity was increased in anoxically germinated rice coleoptiles (Mertens et al., 1990; Kato-Noguchi, 2002) and anoxic rice suspension cells (Mohanty et al., 1993), whereas PFK activity was unaffected.

Studies on genes encoding the ATP- and PPi-dependent phosphofructokinases have been previously limited by the lack of information on coding sequences for plant PFKs, which were only recently described (Mustroph et al., 2007; Winkler et al., 2007). The Arabidopsis thaliana phosphofructokinase gene family consists of 11 members, of which four members encode PFPs and seven encode PFKs (Nielsen et al., 2004; Mustroph et al., 2007; Winkler et al., 2007). Here, we identify 15 putative phosphofructokinase genes of rice, five encoding PFPs and 10 encoding PFKs, and perform transcriptomic and enzymatic studies to evaluate the contribution of phosphofructokinase genes to anoxic metabolism in roots, stems, and leaves of the highly anoxia-tolerant plant. The analysis includes evaluation of phosphofructokinase gene expression during darkness and illumination, since it was already demonstrated that illumination greatly enhances the tolerance of plants to anoxic stress due to the contribution of photosynthesis to energy production (Mustroph et al., 2006b). The findings indicate that individual members of the PFK and PFP gene families are induced by anoxia, although activities of these two enzymes are only slightly increased by the stress. Notably, the induction of PFP genes was greater in the shoots and leaves than in roots, leading to the suggestion that the induction of the PPi-utilizing phosphofructokinase may only occur in tissues with sufficient carbohydrate levels for consumption during the stress. During the study, mRNA sequences and intracellular localization of the proteins were analyzed, and several discrepancies to the annotated versions were found.

\section{MATERIALS AND METHODS \\ PLANT MATERIAL AND ANOXIC TREATMENT}

Rice seeds (Oryza sativa ssp. indica cv. Cigalon) were watered, germinated for 3 days in the dark at $27^{\circ} \mathrm{C}$ and transferred to pots containing Knop nutrient solution that was continuously aerated (Mustroph and Albrecht, 2003). After growth for 20 days in $16 \mathrm{~h}-$ light $/ 8 \mathrm{~h}$-dark cycles and $250 \mu$ moles photons $\mathrm{m}^{-2} \mathrm{~s}^{-1}$ the plants were placed in desiccators, while their roots were immersed in nutrient solution. The gaseous and the aqueous phase (the nutrient solution) in the desiccator were continuously flushed with nitrogen gas and plants were treated for $0.5,2,8$, or $24 \mathrm{~h}$ in the light $\left(250 \mu\right.$ moles photons $\left.\mathrm{m}^{-2} \mathrm{~s}^{-1}\right)$ or in complete darkness. Additionally, light-grown plants were exposed to $24 \mathrm{~h}$ darkness in ambient air to distinguish between light-dependent and anoxiaindependent gene expression regulation. For harvest, plants were removed from the desiccator, divided into roots, stem and leaf sheaths, and frozen immediately in liquid nitrogen within $60 \mathrm{~s}$.

\section{ISOLATION OF RNA, cDNA SYNTHESIS, AND SEMI-QUANTITATIVE REVERSE-TRANSCRIPTASE POLYMERASE CHAIN REACTION ANALYSIS}

RNA from frozen tissues was extracted using the Trizol reagent (Bioline GmbH, Luckenwalde, Germany). cDNA was synthesized from $15 \mu \mathrm{g}$ RNA with standard protocols using oligodT primers and MLV reverse transcriptase (Fermentas GmbH, St. LeonRot, Germany). The PCR reactions were performed using Taq polymerase (New England Biolabs GmbH, Frankfurt, Germany) according to the purchaser's protocol. The oligonucleotide primers used are listed in Table S1 in Supplementary Material. Because of the high GC content of rice cDNA, for each primer combination the optimal PCR conditions were tested using different concentrations of $\mathrm{MgCl}_{2}$, DMSO, betaine, cycle numbers, and temperatures. The optimal conditions for the semi-quantitative amplification of each fragment from cDNA are summarized in Table S2 in Supplementary Material. PCR products were analyzed by electrophoresis in standard $1 \%$ agarose gels. DNA bands were quantified by use of the program AlphaEaseFC (Alpha Innotech Corporation).

\section{CLONING AND SEQUENCING OF PFKs AND PFPs}

For intracellular localization of the proteins and confirmation of nucleotide sequences, full-length PFKs were amplified from cDNA with VELOCITY DNA polymerase (Bioline, Germany) by use of the primers listed in Table S1 in Supplementary Material and cloned into the vector pDONR221 by use of the Gateway technology (Invitrogen, Germany). The resulting entry clones were completely sequenced by Sanger sequencing and compared to the reference sequences from the rice genome annotation project (Ouyang et al., 2007) ${ }^{1}$. Subsequently, correct clones were transferred via the LR reaction into the vector pEarleyGate 103 (Earley et al., 2006), which had been modified by the addition of one base in order to put the C-terminal GFP into frame. The plasmids were sequenced again to verify the correct frame of the PFK-GFP fusion.

The two sequences OsPFK07 and OsPFK08 did not fully match the annotated mRNA sequences. In this case, several clones and fragments of cDNA as well as of genomic DNA were sequenced, not only from the variety Cigalon, but also from other varieties (Nipponbare, M202, FR13A, CT6241, Dongjin, Hwayoung). For OsPFK07, a new full-length construct was made based on the truncated version of the Cigalon variety.

After the first localization studies and the observation of aggregate formation in transiently transformed tobacco leaves, we also cloned the N-terminal ca. 100 amino acids to obtain truncated PFK sequences by use of the primers listed in Table $S 1$ in Supplementary Material. Here, products were amplified with Phusion DNA Polymerase (Fermentas GmbH, St. Leon-Rot, Germany), and cloned by the Gateway technology into the vector pDONR221 (Invitrogen, Germany). After sequencing, correct sequences were subcloned by the LR clonase into the vector pK7FWG2,0 (Karimi et al., 2002).

For sequencing of PFPs, a major piece of each mRNA sequence was amplified by PCR from cDNA by use of the primers listed in Table S1 in Supplementary Material. The PCR products were directly sequenced and compared to the annotated sequences. Nucleotide sequences differing from the annotated versions were submitted to GenBank with the IDs KC620557-KC620559.

\footnotetext{
${ }^{1}$ http://rice.plantbiology.msu.edu
} 


\section{TRANSIENT TRANSFORMATION OF TOBACCO LEAVES AND INTRACELLULAR LOCALIZATION OF PFKS}

Binary expression vectors containing PFK-GFP fusion constructs were transformed into the Agrobacteria strains LBA4404 (full-length constructs) and GV3103 (N-terminal truncations). Tobacco leaves were transiently transformed by infiltration with Agrobacteria suspensions as described in Bendahmane et al. (2000) and Mustroph et al. (2007). About 3-4 days after infiltration, leaf disks were collected and protoplasts were isolated as previously described (Bayley et al., 1992; Mustroph et al., 2007). GFP fluorescence was analyzed on either protoplasts or undigested leaf disks by confocal laser scanning microscopy using Leica TCS SP2 (Leica, Germany, at $\lambda_{\text {ex }} 488 \mathrm{~nm}, \lambda_{\text {em }} 530-555 \mathrm{~nm}$ for GFP and 650-720 nm for chlorophyll emission).

\section{ENZYME ACTIVITIES}

Plant tissue was ground in liquid nitrogen to a fine powder and extracted in $50 \mathrm{mM}$ Hepes- $\mathrm{KOH}, \mathrm{pH} 6.8$ containing $5 \mathrm{mM}$ $\mathrm{Mg}$ acetate, $5 \mathrm{mM} \beta$-mercaptoethanol, 15\% (v/v) glycerol, $1 \mathrm{mM}$ EDTA, $1 \mathrm{mM}$ EGTA, $5 \mathrm{mM}$ DTT, and $0.1 \mathrm{mM}$ Pefabloc proteinase inhibitor (Boehringer Mannheim, Germany). The homogenate was centrifuged at $13,000 \mathrm{~g}$ at $4^{\circ} \mathrm{C}$ for $15 \mathrm{~min}$. The resulting supernatant was used for spectrophotometric determination of PFK and PFP activities as well as the fermentative enzymes alcohol dehydrogenase $(\mathrm{ADH})$ and pyruvate decarboxylase $(\mathrm{PDC})$ at $340 \mathrm{~nm}$ using a UVIKON photometer (Kontron, Germany).

For the assay of PFK (EC 2.7.1.11), the reaction mixture was $0.1 \mathrm{M}$ Hepes- $\mathrm{KOH}$, pH 7.9 with $2 \mathrm{mM} \mathrm{MgCl}_{2}, 0.15 \mathrm{mM} \mathrm{NADH}$, $7.5 \mathrm{mM}$ fructose-6-phosphate, $1 \mathrm{U}$ aldolase, $1 \mathrm{U}$ triosephosphate isomerase, and $1 \mathrm{U}$ glycerol-3-phosphate-dehydrogenase (SigmaAldrich, Germany). The reaction was started by addition of $2.5 \mathrm{mM}$ ATP. For assay of PFP (EC 2.7.1.90), the same reaction mixture was used with the addition of $1 \mu \mathrm{M}$ fructose-2,6bisphosphate, and initiation of the reaction with $1 \mathrm{mM} \mathrm{NaPPi}$ (modified from Gibbs et al., 2000). PDC (EC 4.1.1.1) was assayed in $50 \mathrm{mM}$ MES, pH 6.8 , with $25 \mathrm{mM} \mathrm{NaCl}, 1 \mathrm{mM} \mathrm{MgCl} 2,0.5 \mathrm{mM}$ thiamine pyrophosphate, $2 \mathrm{mM}$ dithiothreitol, $0.17 \mathrm{mM} \mathrm{NADH}$, $50 \mathrm{mM}$ sodium oxamate, $10 \mathrm{U} \mathrm{ADH}$ (Sigma-Aldrich, Germany) and the reaction was initiated by addition of $10 \mathrm{mM}$ pyruvate (Waters et al., 1991). ADH (EC 1.1.1.1) was assayed in 50 mM TES buffer, $\mathrm{pH} 7.5$, with $0.2 \mathrm{mM} \mathrm{NADH}$ and the reaction was initiated by the addition of $10 \mathrm{mM}$ acetaldehyde (Waters et al., 1991). Protein concentration was measured according to Bradford (1976).

\section{BIOINFORMATICS AND STATISTICS}

Nucleotide and protein sequences were analyzed by use of the program Bioedit (Tom Hall, Ibis Biosciences, Carlsbad, USA). ClustalW alignments were done with the website http: //www.genome.jp/tools/clustalw/. Phylogenetic trees were constructed by use of the website http://www.phylogeny.fr/version2_ cgi/phylogeny.cgi. Expression data from rice microarray experiments were obtained from Mustroph et al. (2010), and heat maps were drawn with TIGR-MeV (Saeed et al., 2006).

Polymerase chain reaction analyses were performed on three independent bioreplicates. Infiltration of tobacco leaves was repeated three to five times for each construct. Enzymatic measurements were done with three independent bioreplicates, and results were statistically analyzed with the package "multcomp" in R by use of the Tukey HSD test.

\section{RESULTS IDENTIFICATION OF GENES ENCODING PHOSPHOFRUCTOKINASES IN RICE AND COMPARISON OF THEIR SEQUENCES}

The Arabidopsis phosphofructokinase-encoding gene sequences were used to perform a BLAST-search of the rice genome (Ouyang et al., 2007 $)^{2}$ for homologous nucleotide sequences. This analysis identified 15 different sequences with high similarity to Arabidopsis phosphofructokinase-encoding genes. A phylogenetic tree based on the amino acid sequences was generated, including the sequence of phosphofructo-2-kinase/fructose-2,6-bisphosphatase, which is a similar, but unrelated protein (Figure 1). Four of the rice proteins (LOC_Os02g48360, LOC_Os06g22060, LOC_Os08g25720, LOC_Os09g12650) grouped with the two putative Arabidopsis PFP-alpha subunits (At1g20950, At1g76550) and known PFPalpha subunits from other plants. Surprisingly, two rice PFPalpha protein sequences (LOC_Os08g25720, LOC_Os09g12650) were found to be distinct from the PFP-alpha subunit sequences of dicotyledonous species known so far (Figure 1). One rice amino acid sequence (LOC_Os06g13810) showed high homology to the two putative Arabidopsis PFP-beta subunits (At1g12000, At4g04040) and the PFP-beta subunits from Citrus $\times$ paradisii, potato and Ricinus communis.

The remaining 10 rice phosphofructokinases grouped with seven Arabidopsis PFK proteins, indicating that both species have larger families of ATP-dependent than PPi-dependent phosphofructokinases. Based on the sequence similarities among the PFK family, three sub-clades were distinguished (Figure 1). One group includes five rice (LOC_Os01g09570, LOC_Os01g53680, LOC_Os05g10650, LOC_Os05g44920, LOC_Os06g05860) and five Arabidopsis PFKs, the two other groups have each one Arabidopsis member (At2g22480, At5g47810), and two (LOC_Os04g39420, LOC_Os09g30240), or three (LOC_ Os08g34050, LOC_Os09g24910, LOC_Os10g26570) rice members, respectively (Figure 1). Based on these results, we propose to distinguish the three PFK sub-clades as PFK_A, PFK_B, and PFK_C (Table 1). The amino acid alignment reveals distinct sequence patterns with high similarity among the members of each sub-clade that differentiate them from the other two sub-clades (Figure S1 in Supplementary Material). Besides other sequence differences, members of group B have shorter $\mathrm{N}$ - and C-termini, whereas members of group $\mathrm{C}$ have shorter $\mathrm{C}$-termini compared to group A members. Furthermore, all members of group $\mathrm{C}$ are predicted to be localized to plastids (Table 1; TargetP, Emanuelsson et al., 2000; pSort, Horton et al., 2006).

\section{EXPRESSION OF PHOSPHOFRUCTOKINASE GENES UNDER AERATION}

To study the expression patterns of all representatives of the rice phosphofructokinase gene family, transcript abundance was analyzed by use of semi-quantitative reverse transcription polymerase chain reaction (RT-PCR) using total RNA from roots, leaf sheaths, and stems of rice seedlings grown under non-stress conditions in

\footnotetext{
${ }^{2}$ http://rice.plantbiology.msu.edu
} 


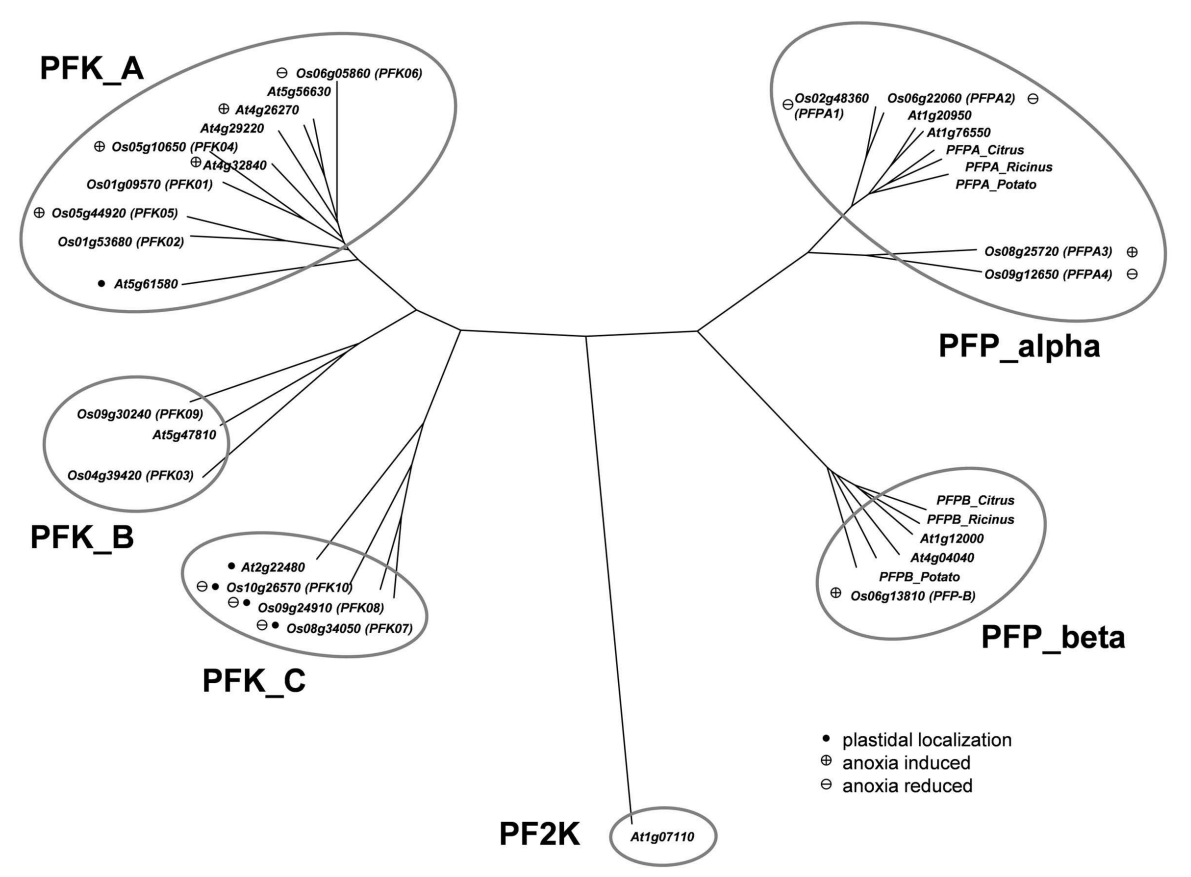

FIGURE 1 | Phylogeny of plant phosphofructokinase genes. Unrooted neighbor joining tree produced from CLUSTALW alignment of amino acid sequences of Arabidopsis and rice phosphofructokinase genes. Genes marked with a "plus" showed increased transcript levels and names marked with a "minus" showed decreased transcript levels during anoxic stress treatment, respectively. Arabidopsis genes marked with a plus are those that were induced by $>2$-fold in published microarray experiments (Mustroph et al., 2010). Genes marked with a black dot are plastid localized. PF2K: Arabidopsis phosphofructo-2-kinase gene (At1g07110) used as an outgroup in the phylogenetic analysis. Accession numbers for other plant PFPS: Citrus_Alpha, AAC67587; Potato_Alpha, P21342; Ricinus_Alpha, Q41140; Citrus_Beta, AAC67586; Potato_Beta, P21343; Ricinus_Beta, Q41141. the light or after transfer to complete darkness for $24 \mathrm{~h}$ (labeled as $0 \mathrm{~h}^{*}$ in Figure 2). The abundance of actin mRNA was used as a loading control (Ren et al., 2005). The accumulation of some transcripts encoding PFKs and PFPs were organ-specifically and/or light-dependently regulated, while others exhibited ubiquitous expression patterns. mRNAs for OsPFK01 - OsPFK03, OsPFK05 OsPFK08, and OsPFK10 were detected in all analyzed organs of seedlings exposed to light, as well as transcripts of OsPFPA1 and OsPFPA4 (Figure 2). OsPFK04 and OsPFK09 mRNAs were present at low levels in tissues of non-stressed seedlings during both light and dark exposure ( $0 \mathrm{~h}$ anoxia). OsPFPA2 was strongly expressed in the stem, and OsPFPA3 as well as OsPFP-B showed lower expression in leaves than in roots and stems. The transfer of seedlings to darkness for $24 \mathrm{~h}$ resulted in a decrease in transcripts encoding OsPFPA4 in all tissues, and OsPFK07 and OsPFPA1 in leaves $\left(0 \mathrm{~h}^{*}\right.$ in Figure 2). OsPFPA3 transcript levels were slightly enhanced during darkness, whereas transcripts of OsPFK01 - OsPFK03, OsPFK05, OsPFK06, OsPFK08, OsPFK10, OsPFKPFPA2, and OsPFKPFP-B accumulated to similar extent during dark and light growth.

\section{EXPRESSION OF PHOSPHOFRUCTOKINASE GENES UNDER ANOXIA IN LIGHT AND DARKNESS}

To identify the phosphofructokinase genes that may play a tissue specific role in the response to anoxic metabolism in rice seedlings, transcript levels of the 10 PFK and 5 PFP genes were quantified in seedling tissues following exposure to anoxia (30 $\mathrm{min}$ to $24 \mathrm{~h}$ ), in the light or complete darkness. The pyruvate decarboxylase (PDC1, LOC_Os05g39310) transcript, which is known to significantly increase in abundance under low-oxygen conditions in rice seedlings, was monitored as positive control for anoxic stress (Figure 2). Under normoxic conditions, the PDC1 mRNA was more abundant in roots as compared to stems and leaves. PDC1 transcript level increased within 30 min of anoxia stress in roots, whereas the increase in stems and leaves was detected after $2 \mathrm{~h}$ of stress. PDC1 transcripts were induced by anoxia in roots and leaves with similar kinetics in seedlings exposed to light or darkness. In stems, the induction of PDC was slightly faster in darkness than during light irradiation.

The evaluation of anoxic stress-responsive mRNA accumulation of the rice $P F K$ and $P F P$ genes identified three groups. Expression of group 1 phosphofructokinase genes (OsPFK01, OsPFK02, OsPFK03) did not change during stress treatment (Figure 2). Group 2 phosphofructokinase genes (OsPFK06, OsPFK07, OsPFK08, OsPFK10, OsPFPA1, OsPFPA2, OsPFPA4) showed a decrease in transcript levels in response to anoxia. Among these genes, OsPFK10 and OsPFPA2 transcripts were reduced in stems only after $24 \mathrm{~h}$ anoxia in darkness, whereas the transcript abundance of the other five genes reduced more rapidly. OsPFK06 transcripts decreased in roots and stems, whereas OsPFK07, OsPFK08, OsPFPA1, and OsPFPA4 transcripts decreased in all analyzed tissues. Interestingly, all $P F K$ genes in group 2 that showed reduced expression under anoxia are predicted to be plastid-localized (Table $\mathbf{1}$ ). 
Table 1 | Rice phosphofructokinase genes, Locus identifier, length of coding sequence (number of bases), and protein size (number of amino acids).

\begin{tabular}{|c|c|c|c|c|c|c|}
\hline \multirow[t]{2}{*}{ Locus ID } & \multirow[t]{2}{*}{ Name } & \multirow[t]{2}{*}{ Length of mRNA } & \multirow[t]{2}{*}{ Length of protein } & \multirow[t]{2}{*}{ Predicted localization } & \multicolumn{2}{|c|}{$\begin{array}{l}\text { RNAseq expression } \\
\text { level from } 16 \text { tissues }\end{array}$} \\
\hline & & & & & Maximum & Mean \\
\hline \multicolumn{7}{|l|}{ PFK_A } \\
\hline LOC_Os01g09570 & OsPFK01 & 1596 & 531 & Cytosolic & 69.04 & 27.60 \\
\hline LOC_Os01g53680 & OsPFK02 & 1683 & 560 & Cytosolic & 44.50 & 10.24 \\
\hline LOC_Os06g05860 & OsPFKO6 & 1677 & 558 & Plastid (confirmed cytosolic) & 118.48 & 33.60 \\
\hline \multicolumn{7}{|l|}{ PFK_B } \\
\hline LOC_Os04g39420 & OsPFKO3 & 801 & 266 & Cytosolic & 46.80 & 6.89 \\
\hline LOC_Os09g30240 & OsPFKO9 & 1398 & 465 & Cytosolic & 48.42 & 5.79 \\
\hline \multicolumn{7}{|l|}{ PFK_C } \\
\hline \multicolumn{7}{|l|}{ PFP-ALPHA } \\
\hline LOC_Os02g48360 & OsPFPA1 & 1854 & 617 & Cytosolic & 98.49 & 19.19 \\
\hline LOC_Os06g22060 & OsPFPA2 & 1869 & 622 & Cytosolic & 171.15 & 53.64 \\
\hline LOC_Os08g25720 & OsPFPA3 & 1854 & 617 & Cytosolic & 102.03 & 42.51 \\
\hline LOC_Os09g12650 & OsPFPA4 & $1884(1722)$ & $627(573)$ & Cytosolic & 0.68 & 0.36 \\
\hline \multicolumn{7}{|l|}{ PFP-BETA } \\
\hline LOC_Os06g13810 & OsPFP-B & 1704 & 567 & Cytosolic & 110.02 & 52.99 \\
\hline
\end{tabular}

Numbers for OSPFKO7 are for the sequence of the variety FR13A. Numbers in brackets are annotated sizes from the rice genome annotation project (http: //rice.plantbiology.msu.edu; Ouyang et al., 2007). Intracellular localization was predicted by use of two online programs (Target?, Emanuelsson et al., 2000; pSort, Horton et al., 2006). RNAseq expression data are from the Nipponbare variety from 16 tissues, summarized from the rice genome annotation project (http://rice.plantbiology.msu.edu/expression.shtm/).

Phosphofructokinase genes of group 3 were induced under anoxia (OsPFK04, OsPFK05, OsPFPA3, OsPFP-B). OsPFK09 is also included in group 3 , but displayed a markedly delayed increase in mRNA accumulation in response to stress at an extremely low expression level. OsPFK04, predicted to encode a cytosolic enzyme, expresses the strongest anoxia-induced transcript of group 3. OsPFK04 mRNA content was below the detection level in seedlings grown under aerated conditions, but increased dramatically within 30 min of anoxia in roots resembling the pattern of PDC1 accumulation. OsPFK05 mRNA accumulated less dramatically only in leaves after $2-24 \mathrm{~h}$ of anoxia. Among the PFP genes, only the content of OsPFPA3 and OsPFP-B mRNAs slightly increased in leaves and stems after $2 \mathrm{~h}$ of anoxia (Figure 2), resembling the expression of OsPFK05. The group 2 and group 3 phosphofructokinase genes are highlighted in the phylogenetic tree with a minus or plus sign, respectively, for their low-oxygen stress responsiveness (Figure 1).

Exposure to light or darkness most dramatically altered mRNA content of group 2 genes of the phosphofructokinase family. These genes showed a higher decrease in transcript levels in response to anoxia in darkness as compared to anoxia during illumination. OsPFPA1 and OsPFPA4 mRNA content was reduced during dark anoxia most likely in response to the transfer to darkness, as $24 \mathrm{~h}$ dark incubation under constant aeration (sample $0 \mathrm{~h}^{*}$ in Figure 2) caused a similar loss of the mRNA level. On the other hand,
OsPFK06, OsPFK07, OsPFK08, OsPFK10, and OsPFPA2 transcript levels were decreased stronger during anoxia in darkness than in light, but not during darkness alone.

\section{SEQUENCE VARIATIONS OF PHOSPHOFRUCTOKINASE GENES}

Amplification and sequencing of $P F K$ genes revealed in the OsPFK07 and OsPFK08 sequences a significant difference to annotated sequences. OsPFK08 was annotated with two splicing forms

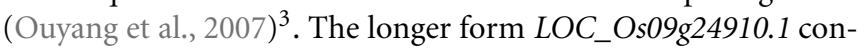
tained a sequence that was not present in any other sequence of the group PFK_C (Figure 3A; Figures S1 and S2 in Supplementary Material). Sequencing of several cDNA clones derived from RNA of different rice varieties revealed the unique presence of the shorter annotated splicing form, LOC_Os09g24910.2 (Figure 3A and data not shown). OsPFK07 surprisingly revealed the lack of 20 nucleotides in its mRNA sequence in comparison to the annotated version, leading to a frame shift in the translated protein sequence and a premature stop codon (Figure 3B). We re-sequenced the OsPFKO7 cDNA and genomic DNA of several rice varieties in order to confirm the initial findings. Genomic clones of OsPFK07 of all varieties consistently resulted in the complete annotated

\footnotetext{
${ }^{3}$ http://rice.plantbiology.msu.edu
} 


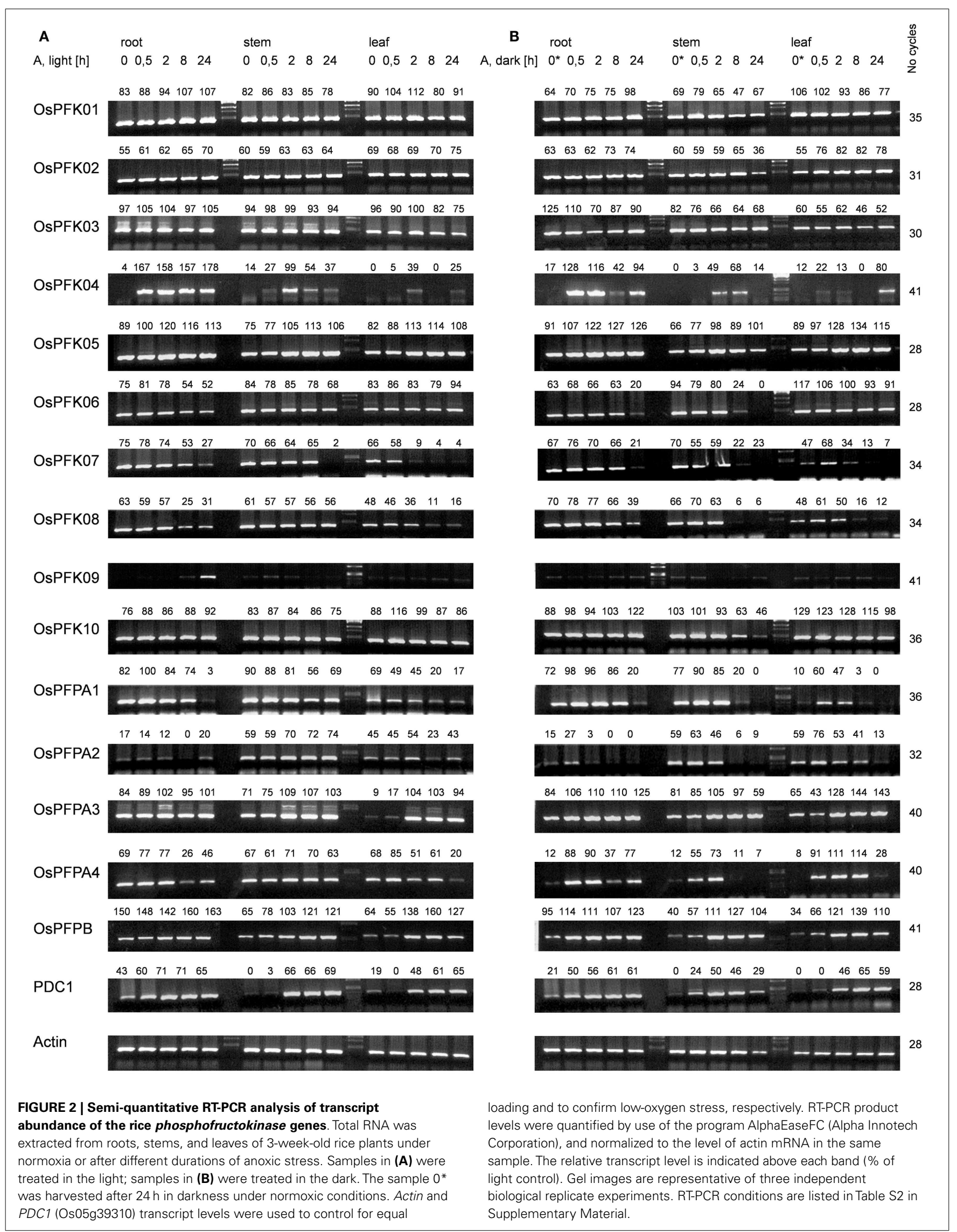




\section{A PFK07 \\ PFK07 mod Nipp PFK07-mod FR13A PFK08.1 \\ PFK08 2 \\ PFK08 mod \\ PFK10}

Clustal Consensus

\section{PFK07}

PFK07_mod_Nipp

PFK07 mod FR13A

PFK08.1

PFK08.2

PFK08 mod

PFK10

Clustal Consensus
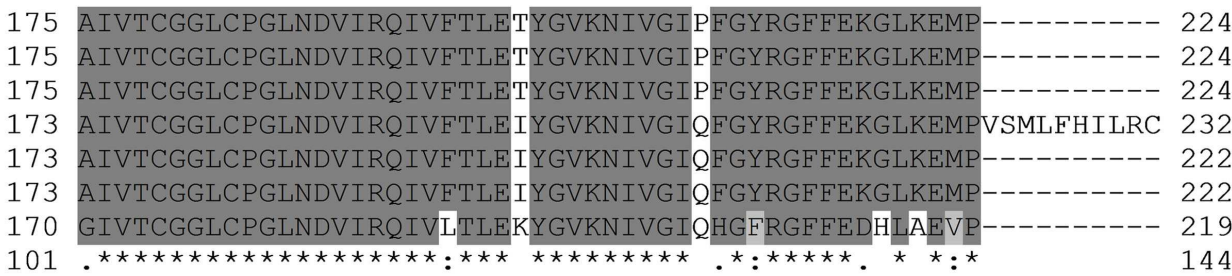

224

224

224

233

222

222

219

144

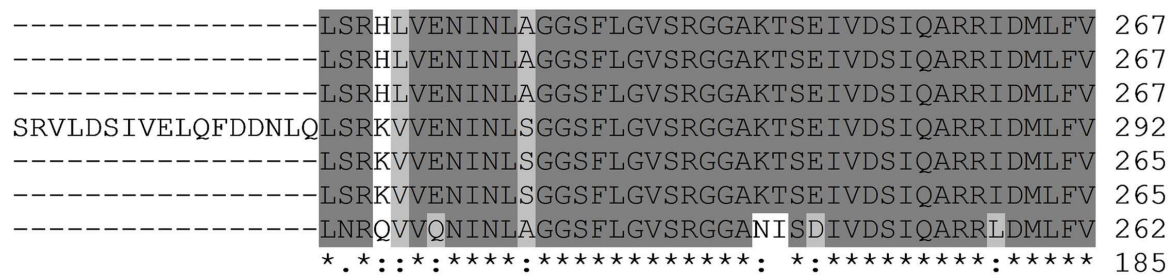

388 LKTKGFCVVCVAEAAGQLFYVHYRSLQKSGATDASGNVILSDIGVHMQQKIKMHFKDIGV 388 LKTKGFCVVCVAEAAGOEFTKIRCNRCIWKCDT--_-_-_-_-_-_-_-_-_-_-_-- 420 388 LKTKGFCVVCVAEAAGQELLQKSGATDASGNVILS------DIGVHMQQKIKMHFKDIGV 441 413 LEKKGFCVVCVAEGAGQDLLQKSNATDASGNVILS------DFGVHMQQKIKSHFKDIGV 466 386 LEKKGFCVVCVAEGAGQDLLQKSNATDASGNVILS------DFGVHMQQKIKSHFKDIGV 439 386 LEKKGFCVVCVAEGAGQDLLQKSNATDASGNVILS------DFGVHMQQKIKSHFKDIGV 439 383 IETKGFALICVAEGAGQEHLQQSNATDASGNMILG------DIGVHLHQKIKAHFKEIGV 436

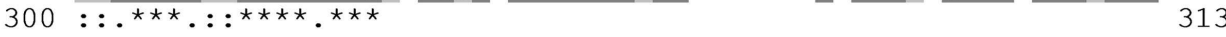

Clustal Consensus

PFK07

PFK07_mod_Nipp PFK07 mod FR13A PFK08.1

PFK08. 2

PFK08 mod

PFK10

Clustal Consensus

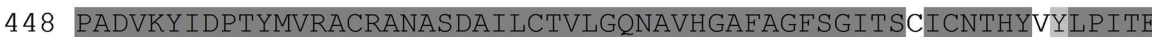

442 PADVKYIDPTYMVRACRANASDAILCTVLGQNAVHGAFAGFSGITSCICNTHYVYLPITE 501

467 PADVKYIDPTYMVRACRANASDAILCTVLGQNAVHGAFAGFSGITSGICNTHYAFLPITE 526

440 PADVKYIDPTYMVRACRANASDAILCTVLGQNAVHGAFAGFSGITSGICNTHYAFLPITE 499

440 PADVKYIDPTYMVRACRANASDAILCTVLGQNAVHGAFAGFSGITSGICNTHYAFLPITE 499

437 HSDVKYIDPTYMVRAVRANASDAILCTVLGQNAVHGAFAGFSGITTGICNTHNVYLPISE 496

313
C PFPA4

PFPA4 mod

PFPA3

PFPA1

PFPA2

Clustal Consensus

PFPA4
PFPA4 mod
PFPA3
PFPA1
PFPA2
Clustal Consensus

PFPA4

PFPA4 mod

PFPA3

PFPA1

PFPA2

Clustal Consensus

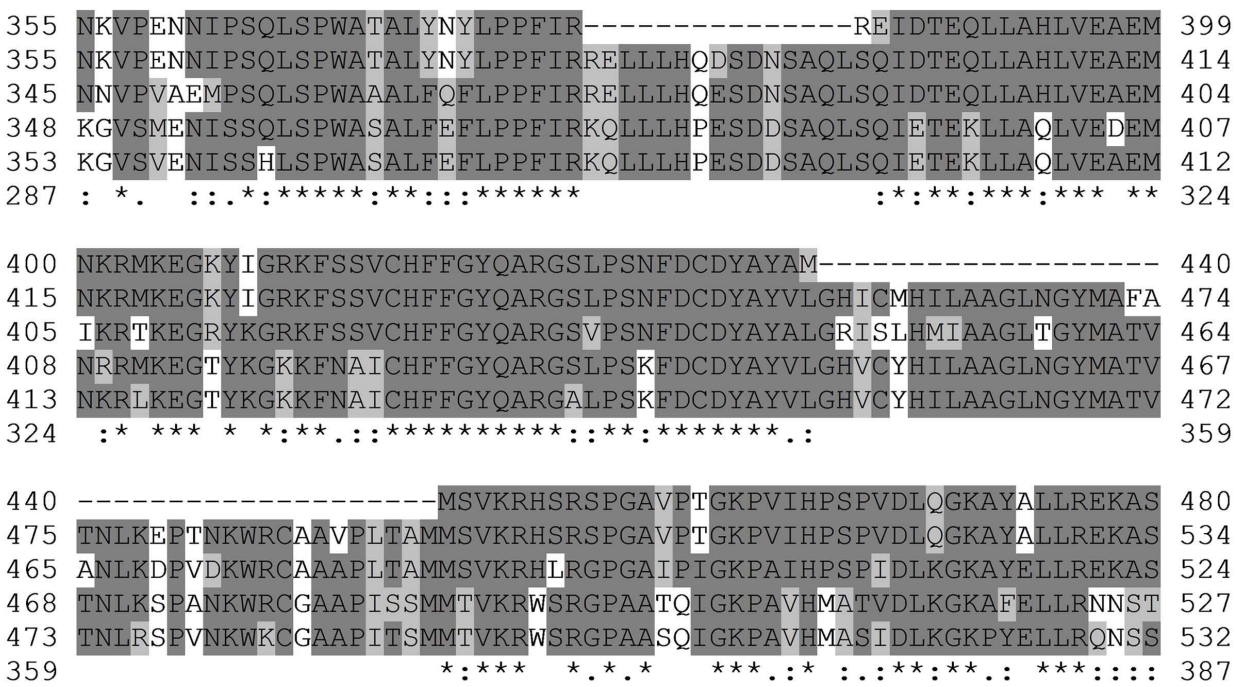

Full-length nucleotide and protein sequences can be found in Figure S2 in Supplementary Material. (A) Two splicing forms of OsPFK08; (B) modified splicing for OSPFKO7, leading to a frame shift in the protein, and the modified sequence in the rice variety FR13A; (C) modified splicing of OSPFPA4. 
sequence including the 20 nucleotide region, while sequencing of the OsPFK07 cDNA of these varieties gave always rise to a truncated sequence lacking this stretch of 20 nucleotides. As result, a truncated protein lacking 120 amino acids at the C-terminus is predicted to be most likely non-functional. Supposedly, this mutation could occur in the rice genome since two other members of the PFK_C are available, while Arabidopsis only contains one isoform of this subgroup (Figure 1). In consistency with a putative non-functional gene, the expression level of OsPFK07 is very low in many tissues, as derived for example from RNAseq analyses (Table 1). However, this finding was not confirmed in our experiments (Figure 2).

Interestingly, two rice varieties, FR13A and CT6241, revealed a second modification of the OsPFK07 gene, an insertion of two bases in the genomic sequence close to the modified splicing site (Figure S2 in Supplementary Material). This altered sequence restores the reading frame comparable to OsPFK08 and OsPFK10 (Figure 3B). However, which of the two sequence variants evolved earlier during evolution remains to be explored in future.

Our sequencing revealed also a modified OsPFPA4 nucleotide sequence. The annotated sequence lacks part of the final coding sequence leading to encoded PFP-alpha subunit with a truncated C-terminus in comparison to the other three isoforms. However, the sequencing results revealed another mRNA sequence that represents an un-annotated alternative splicing form, which more closely resembles the sequence of the other three homologous genes (Figure 3C; Figure S2 in Supplementary Material). Interestingly, the expression level of OsPFPA4 was very low in rice tissues as observed by RNAseq analyses (Table 1), but in our analyses OsPFPA4 was significantly expressed in detectable amounts in seedlings (Figure 2).

\section{INTRACELLULAR LOCALIZATION OF PFKs}

The expression analysis under anoxia revealed decreased expression of several $P F K$ genes, in particular those representatives that encode putative plastid-localized proteins. We therefore aimed to confirm the intracellular localization of PFK isoforms, and applied a similar approach as previously shown for Arabidopsis PFKs (Mustroph et al., 2007). Using the leaf infiltration technique for transient transformation of the rice $P F K$ genes in tobacco leaves, we showed the clear localization of 5 out of 10 different PFK isoforms in the cytoplasm. Expression of the full-length PFKs of OsPFK01, OsPFK02, OsPFK04, OsPFK05, and OsPFK06 resulted in their cytosolic localization (Figure $S 3$ in Supplementary Material), but the proteins formed cytoplasmic aggregates. Several modified protocols of transient transformation were tested, but resulted always in the production of aggregates: changes in incubation time of transiently transformed tobacco leaves, at different temperatures, use of different Agrobacteria strains and binary vectors, and ultimately stable transformation in Arabidopsis (data not shown). However, expression of fusion proteins containing the first 100 amino acids of the respective PFK protein resulted in even distribution throughout the cytosol (Figure 4). Surprisingly, OsPFK06, which was predicted to be plastid-localized, was clearly cytosolic (Figure 4E). As a very short transit peptide of only 10 amino acids was predicted (TargetP, Emanuelsson et al.,
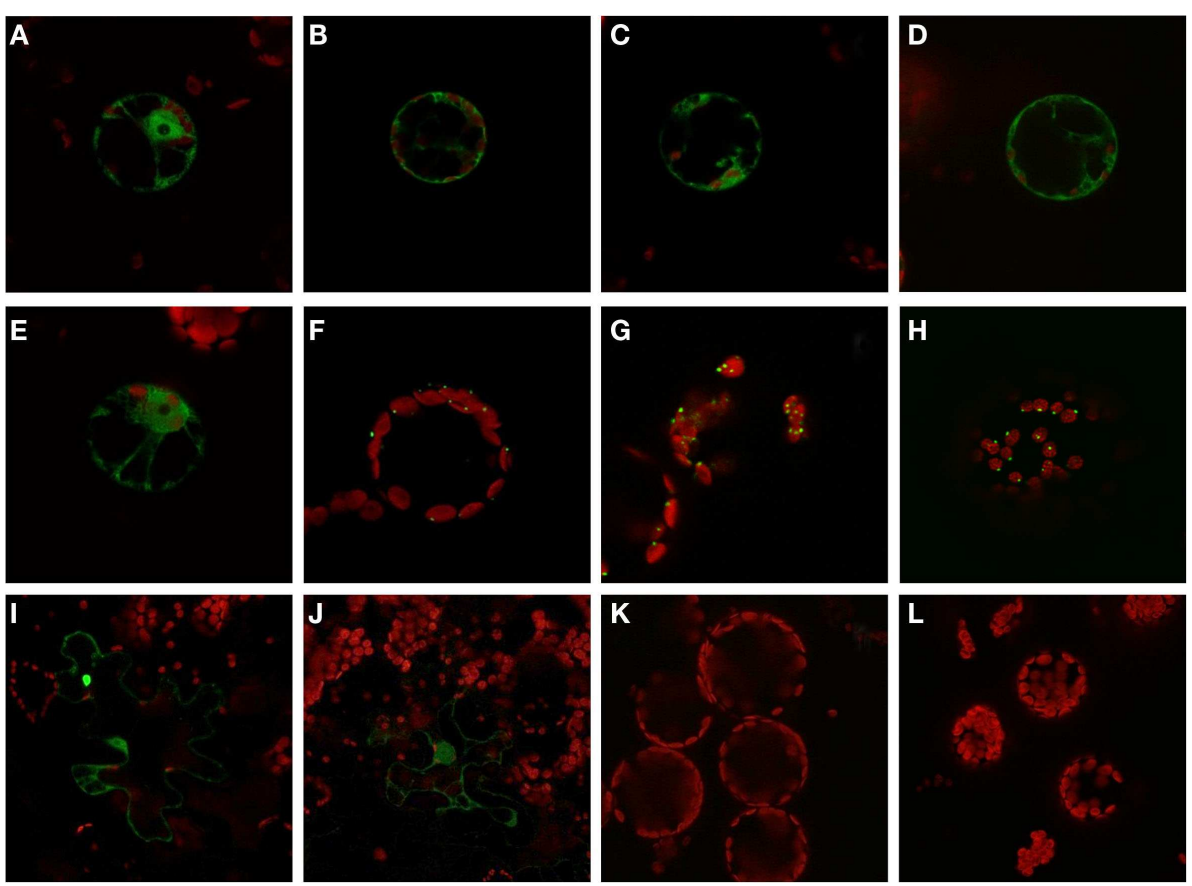

FIGURE 4 | Subcellular localization of PFK isoforms from rice. Full-length mRNA sequences or the N-terminal part of the sequences were cloned in frame in front of a GFP-coding sequence and were transiently transformed into tobacco leaves by Agrobacterium infiltration. After 3-4 days, protoplasts or undigested leaf disks were isolated and analyzed by confocal microscopy. Green color represents GFP fluorescence, red color represents chlorophyll autofluorescence. N-terminal part: (A) OsPFK01; (B) OsPFK02; (C) OsPFK04; (D) OsPFK05; (E) OsPFK06; (K) OsPFK08, (L) OsPFK10. Full-length CDS: (F) OsPFK07; (G) OsPFK08; (H) OsPFK10; (I) OsPFK03; (J) OsPFK09. 
2000), it is suggested that the organellar localization is a false prediction.

OsPFK03 and OsPFK09 are both members of the weakly expressed PFK_B subgroup and are mainly expressed in seeds (Figure S4 in Supplementary Material). Tobacco leaves infiltrated with the truncated or full-length constructs p35S::OsPFK03-GFP and p35S::OsPFK09-GFP did surprisingly not show GFP fluorescence in tobacco mesophyll cells in four independent experiments, although the same vectors, bacterial strains and conditions had been used as for the positive control p35S::OsPFK05-GFP. However, we observed GFP fluorescence in a few epidermal cells that demonstrate cytosolic localization of the proteins (Figure 4; Figure S3 in Supplementary Material). It can be concluded that both proteins are less stable during transient overexpression in tobacco leaves than members of the PFK_A group.

All members of the PFK_C group, OsPFK07, OsPFK08, and OsPFK10, were predicted to be localized in plastids, with a predicted transit peptide consisting of 30-50 amino acid residues. Our assay revealed localization of the full-length proteins in plastids, however associated with the formation of aggregates (Figure 4), as previously described for Arabidopsis AtPFK4 and AtPFK5 (Mustroph et al., 2007). Still, we observed clear association of the aggregates with chloroplasts, and not with other compartments (Figure 4; Figures S3S,T in Supplementary Material). Expression of the N-terminal part did not result in detectable plastidal GFP fluorescence (Figures 4K,L).

\section{PHYLOGENETIC ANALYSIS AND EXPRESSION UNDER OXYGEN DEFICIENCY STRESS}

The expression analysis of phosphofructokinase genes of rice under anoxia revealed differential gene expression of several members in roots and shoots of seedlings. For a wider comparison among species, we first identified phosphofructokinase genes in different plant species by use of the Phytozome genome collection ${ }^{4}$, and constructed a separate phylogenetic tree for PFK and PFP sequences (Figures 5 and 6). We selected phosphofructokinase genes from plant genomes, of which expression data are available under oxygen deficiency stress, and additionally used two other monocotyledonous species, Sorghum bicolor and Brachypodium distachyon. Comparison of the genome of the green algae Chlamydomonas reinhardtii revealed the presence of PFK_C genes only, hinting at a complex evolution of phosphofructokinase genes in higher plants. Gene expression data from published microarray experiments were added from rice (Lasanthi-Kudahettige et al., 2007; Narsai et al., 2009; Mustroph et al., 2010), Arabidopsis (Branco-Price et al., 2008; Hsu et al., 2011; Lee et al., 2011), poplar (Kreuzwieser et al., 2009), cotton (Christianson et al., 2010), and soybean (Nanjo et al., 2011). It was intended to obtain a first qualified overview about the potential role of phosphofructokinases under oxygen deficiency stress.

Interestingly, all analyzed monocotyledonous species only contained one gene for the beta-subunit of PFP, while dicotyledonous species usually contained more isoforms. In general, PFPbeta-encoding genes of either monocotyledonous or dicotyledonous species show only a low induction upon low-oxygen stress,

${ }^{4}$ http://www.phytozome.net/ among them the rice $P F P$ - $B$-encoding gene being up to 3.8 times induced in the microarray experiments (Table S3 in Supplementary Material). This induced expression was shown to a similar extent in our experiments (Figure 2). Transcript levels of three PFP-alpha subunit-encoding genes were reduced or unchanged under oxygen deficiency stress in rice, while OsPFPA3 was moderately induced in leaves, as indicated by RT-PCR (Figure 2) and microarray analyses (Figure 5). This latter gene was grouped into a monocotyledonous-specific sub-clade of PFP-alpha subunit encoding sequences. The genes most similar to dicotyledonous species were down-regulated, similar to the PFP-alpha subunit encoding genes of other plant species, whose expression was hardly induced (Figure 5). It would be interesting to analyze if other members of this monocotyledonous-specific subgroup are also induced by oxygen deficiency stress, for example in Sorghum or Brachypodium, or if this induction is specific to the submergence-tolerant rice plant.

Among the PFK gene family, each plant species analyzed contained members that were induced by oxygen deficiency stress (Figure 6), indicating an important function in plant metabolism under the stress condition. Most of the induced genes, among them OsPFK04, OsPFK05, AtPFK3, and AtPFK6, belong to the subgroup PFK_A. The plastidal genes of subgroup PFK_C were generally down-regulated in rice, Arabidopsis and soybean (Figure 6; Table S3 in Supplementary Material). OsPFK06 shows the strongest reduced mRNA content and its encoded PFK isoform is localized in the cytosol (Figure 4E). OsPFK06 was grouped with two other genes from monocotyledonous species, whose expression under oxygen deficiency stress remains to be determined.

\section{ACTIVITY OF PHOSPHOFRUCTOKINASES AFTER ANOXIC TREATMENT}

To further evaluate the relative importance of PFK and PFP during the transition from aerated to anoxic growth conditions in rice seedlings, we measured the specific activities of these two distinct phosphofructokinases along with the fermentative enzymes $\mathrm{ADH}$ and PDC (Table 2). In comparison to anoxically treated plants, the $\mathrm{ADH}$ showed the lowest basal activity in leaves in ambient oxygen concentration, whereas PDC activity was low in all tissues. Illumination did not affect the basal ADH and PDC activity, but the anoxic induction of these enzymes was more pronounced in illuminated seedlings than in darkness. As expected, a significantly elevated $\mathrm{ADH}$ activity was observed after $24 \mathrm{~h}$ of anoxia in all tissues. ADH activity increased threefold to ninefold during the 24-h anoxic treatment. Thereby, the greatest increase of activity was observed in leaves relative to the low basal level in this organ. Also for PDC activity, a significant anoxia-induced elevation was determined after $24 \mathrm{~h}$ of anoxia (Table 2).

Evaluation of PFK activity revealed a decline of 20 and $50 \%$ PFK activity after $24 \mathrm{~h}$ dark incubation under normoxia in comparison to the illuminated control in stems and leaves, respectively. By contrast, PFP activity was not modified upon the transfer of seedlings to darkness (Table 2). In general, PFP and PFK activities did only moderately change during anoxic treatment. PFK activity in stems was significantly higher after 4 and $24 \mathrm{~h}$ of anoxia in light and in dark anoxic treatment as compared to the respective control (Table 2), which likely results from increased expression of OsPFK05 in this tissue (Figure 2). PFK activity did not change 


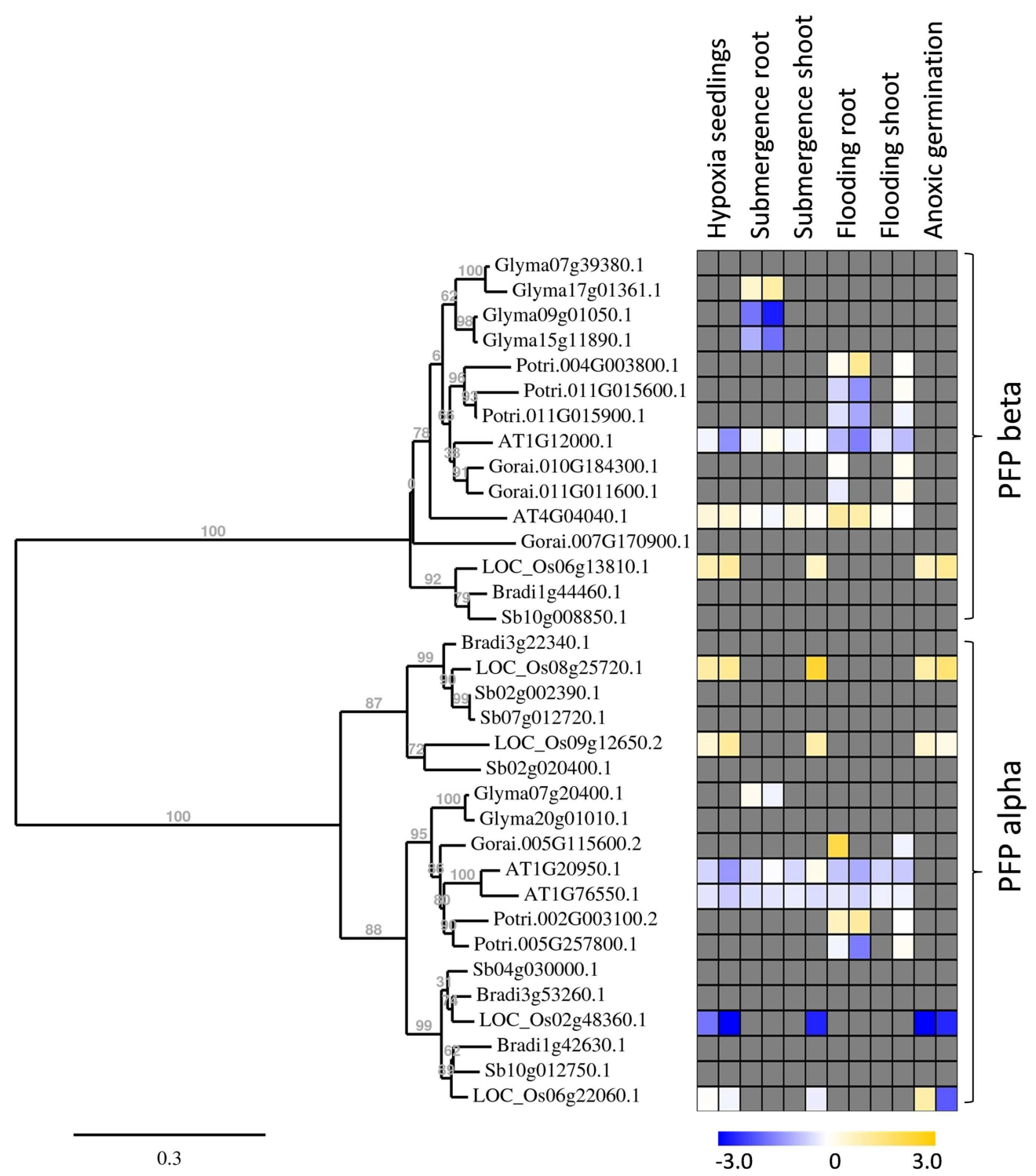

FIGURE 5 | Phylogenetic tree of plant PFP genes, constructed by the platform http://www.phylogeny.fr (Dereeper et al., 2008). Protein sequences were obtained from Phytozome, with modifications after sequencing of rice genes. Gene expression data were collected into a heat map, when available. Data are from the following sources: Hypoxia seedlings: Arabidopsis (Branco-Price et al., 2008, 2 and 9 h), rice (Narsai et al., 2009, 3 and 6 h);
Submergence root/shoot: Arabidopsis (Lee et al., 2011, 7 and 24 h), rice (Mustroph et al., 2010, 24 h shoot); soybean (Nanjo et al., 2011, 6 and $12 \mathrm{~h}$, roots only); Flooding root/shoot: Arabidopsis (Hsu et al.,

2011, 3 and 12 h), cotton (Christianson et al., 2010, $4 \mathrm{~h}$ root and $24 \mathrm{~h}$ shoot), poplar (Kreuzwieser et al., 2009, 5 and $24 \mathrm{~h}$ root, $168 \mathrm{~h}$ shoot); Anoxic germination: rice (Narsai et al., 2009, $24 \mathrm{~h}$; Lasanthi-Kudahettige et al., 2007, 96 h). significantly in response to anoxia in roots or leaves. The activity of PFP was slightly but not significantly increased in leaves only after $24 \mathrm{~h}$ of anoxia in light and darkness (Table 2), but not in roots or stems.

\section{DISCUSSION \\ PHOSPHOFRUCTOKINASE GENES IN RICE AND THEIR EXPRESSION UNDER NORMOXIC CONDITIONS}

In this report we analyzed the expression of 15 phosphofructokinase genes in rice (Table 1). Five gene sequences resemble PFP genes derived from other plant species, which have been described earlier (Carlisle et al., 1990; Todd et al., 1995; Kapri et al., 2000; Suzuki et al., 2003). Genes encoding the two different subunits of the heterotetrameric PFP were found in the rice genome (Figure 1). Whereas Arabidopsis possesses two genes each encoding the PFPalpha and PFP-beta subunits (Mustroph et al., 2007), available rice sequence data predicts four genes for PFP-alpha subunits, which represent the regulatory PFP subunit (Table 1), and one gene encoding the PFP-beta subunit (PFP-B, LOC_Os06g13810) representing the catalytically active subunit of the PFP complex 


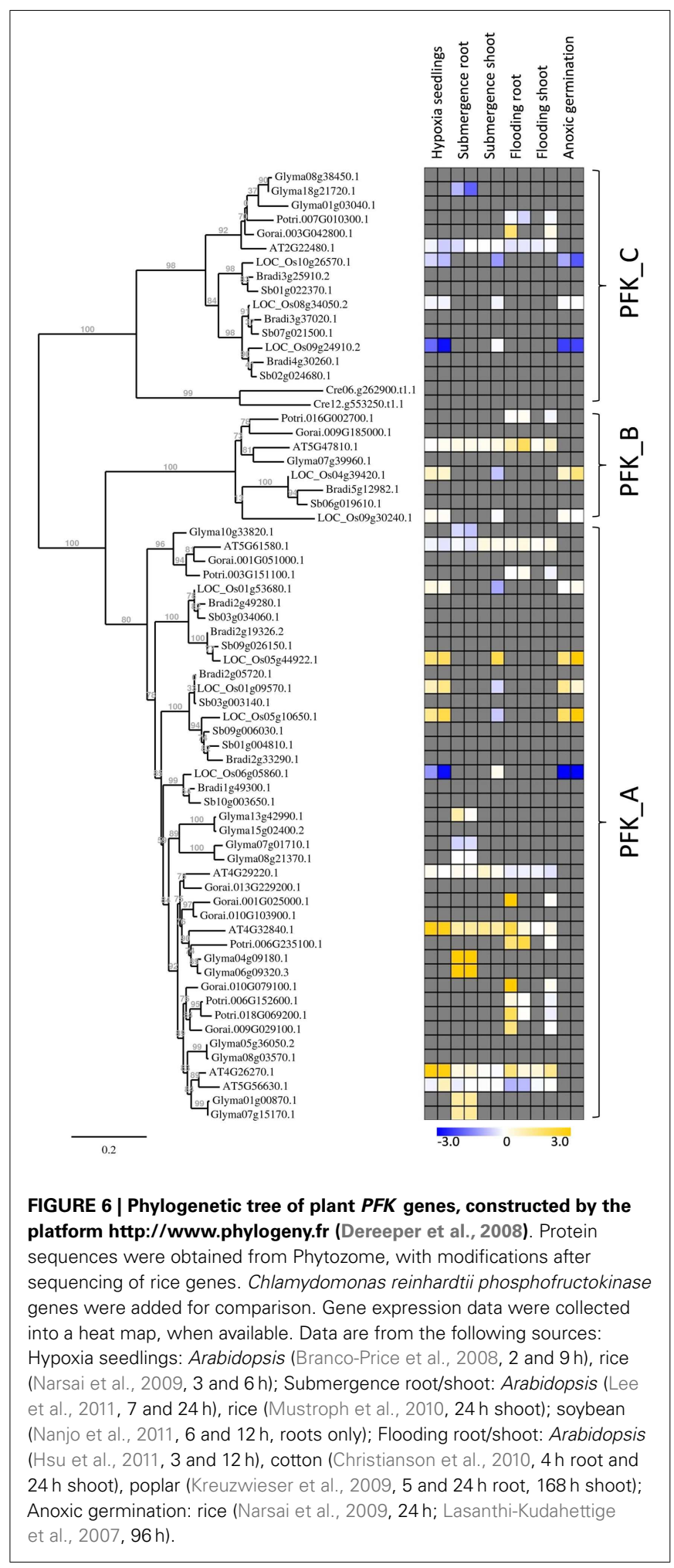

(Yan and Tao, 1984; Theodorou et al., 1992; Theodorou and Plaxton, 1996). It is suggested that rice uses several regulatory subunits with distinct properties that are activated under different growth conditions. Indeed, the four OsPFPA genes show diverse expression patterns in plant tissues and under various light conditions (Figure 2). OsPFPA2 mRNA was detected primarily in stems, whereas OsPFPA1 and OsPFPA3 mRNAs were less abundant in leaves than in stems or roots (Figure 2). PFP activity was very low in leaf extracts compared to that of roots and stems (Table 2). Furthermore, OsPFPA1 and OsPFPA4 showed darkdependent decreases in mRNA accumulation in leaves (Figure 2), but the PFP activity after dark incubation was unchanged in comparison to light-grown leaves (Table 2). These observations in rice are consistent with the previous report of decreased abundance of two Arabidopsis PFP gene transcripts (At1g12000, At1g20950) after transfer to darkness, although no apparent change in PFP activity was determined (Gibon et al., 2004). We predict that the total in vitro enzymatic activity from whole cell extracts conceals the biologically significant differences in the assembly of PFP heterotetrameric complexes in response to the cell-specific variation of the expression of PFP isoforms.

The other 10 phosphofructokinase genes (Table 1) showed homology to the seven AtPFK genes (Mustroph et al., 2007) (Figure 1). Five of these proteins form a sub-clade, designated the PFK_A group, together with the five AtPFK proteins that are important for cytosolic glycolysis (Figure 1). The present study confirms that four of these rice genes are highly expressed in all observed tissues, with the exception of OsPFK04 (Figure 2). Interestingly, the rice genome does not contain a true plastidal isoform in this subgroup, since the predicted plastidal OsPFK06 of the PFK_A group was clearly cytosolic (Figure 4E), while AtPFK4 presents a plastidal isoform in the PFK_A group. The rice PFK_C group members apparently fulfill the sole plastidal PFK function (see below).

The protein sequences of the PFK_B and PFK_C groups markedly differ from the sequences of the group PFK_A (Figure 1; Figure S1 in Supplementary Material). OsPFK03 and OsPFK09 were closely related to AtPFK2 (At5g47810), and form the PFK_B group (Figure 1). The protein sequences of the PFK_B group are shorter than the other PFK sequences (Table 1; Figure S1 in Supplementary Material). AtPFK2 is specifically expressed in seeds, but scarcely expressed in other tissues, and the same expression pattern was determined for both rice genes (Figure S4 in Supplementary Material; Winter et al., 2007). Nevertheless, in our transcript analysis OsPFK03 was expressed at considerable amounts, while OsPFK09 transcripts were present only at very low levels in vegetative tissues (Figure 2). All members of this sub-clade are localized to the cytosol (Figure 4, Mustroph et al., 2007). It is proposed that PFK_B members are characterized by distinct enzymatic properties for specific tissues, such as seeds and embryos. But, expression of AtPFK2 in tobacco leaves did not induce enhanced PFK activity under our assay conditions (Mustroph et al., 2007). Future analyses of Arabidopsis and rice mutants with deficiency in AtPFK2 and OsPFK03/09 expression could shed light on this topic.

The PFK_C subgroup proteins are targeted to plastids and include the rice genes OsPFK07, OsPFK08, and OsPFK10 as well as AtPFK5 (At2g22480; Mustroph et al., 2007; Figure 4). Indeed, $\mathrm{PFK}$ isoforms of various plant species were found in chloroplasts and in the cytosol (Cawood et al., 1988; Knowles et al., 1990; Turner and Plaxton, 2003). While cytosolic PFKs catalyze 
Table 2 | Specific activities of phosphofructokinases (PFK, PFP) and fermentative enzymes (ADH, PDC) (nmol $\left.\times \mathrm{mg} \mathrm{protein}^{-1} \times \mathrm{min}^{-1}\right)$ in roots, stems, or leaves of rice seedlings after 4 and $24 \mathrm{~h}$ of anoxic stress (A), or under normoxic conditions (C).

\begin{tabular}{|c|c|c|c|c|c|}
\hline & & PFK & PFP & ADH & PDC \\
\hline \multicolumn{6}{|c|}{ ROOT } \\
\hline C & 24 h Light & $24.12 \pm 5.45^{a}$ & $94.98 \pm 28.74^{a}$ & $122.26 \pm 30.56^{a}$ & $0.00 \pm 0.00^{\mathrm{a}}$ \\
\hline$A$ & 4 h Light & $20.70 \pm 3.42^{\mathrm{a}}$ & $110.76 \pm 29.55^{a}$ & $212.13 \pm 25.83^{a}$ & $1.12 \pm 0.98^{a}$ \\
\hline$A$ & 4h Dark & $23.03 \pm 7.13^{a}$ & $120.55 \pm 39.30^{a}$ & $256.62 \pm 16.24^{a}$ & $0.75 \pm 1.30^{\mathrm{a}}$ \\
\hline$A$ & $24 \mathrm{~h}$ Light & $31.33 \pm 4.45^{a}$ & $102.21 \pm 11.92^{\mathrm{a}}$ & $980.43 \pm 152.23^{b}$ & $21.95 \pm 2.32^{b}$ \\
\hline \multicolumn{6}{|c|}{ STEM } \\
\hline C & $24 \mathrm{~h}$ Light & $16.55 \pm 1.46^{b c}$ & $135.34 \pm 9.02^{a}$ & $186.27 \pm 17.02^{a}$ & $1.45 \pm 1.87^{a}$ \\
\hline C & 24 h Dark & $12.44 \pm 1.99^{c}$ & $132.30 \pm 10.22^{\mathrm{a}}$ & $183.65 \pm 11.22^{a}$ & $2.29 \pm 0.91^{a}$ \\
\hline$A$ & $4 \mathrm{~h}$ Light & $23.85 \pm 2.72^{\mathrm{a}}$ & $141.81 \pm 12.72^{\mathrm{a}}$ & $325.01 \pm 33.06^{b}$ & $5.47 \pm 1.17^{a}$ \\
\hline$A$ & 4h Dark & $18.33 \pm 2.53^{b}$ & $131.33 \pm 9.61^{a}$ & $207.26 \pm 0.86^{a}$ & $4.38 \pm 1.50^{\mathrm{a}}$ \\
\hline C & 24 h Dark & $5.28 \pm 1.25^{b}$ & $19.94 \pm 1.71^{\mathrm{a}}$ & $24.69 \pm 1.94^{\mathrm{a}}$ & $0.00 \pm 0.00^{a}$ \\
\hline$A$ & $4 \mathrm{~h}$ Light & $12.54 \pm 0.94^{\mathrm{ac}}$ & $22.16 \pm 1.86^{a}$ & $75.60 \pm 4.48^{b}$ & $0.17 \pm 0.21^{a}$ \\
\hline$A$ & 4h Dark & $8.58 \pm 1.54^{b c}$ & $21.39 \pm 2.88^{a}$ & $55.81 \pm 6.78^{\mathrm{ab}}$ & $0.06 \pm 0.11^{a}$ \\
\hline A & $24 \mathrm{~h}$ Light & $13.74 \pm 1.06^{a}$ & $25.55 \pm 3.09^{a}$ & $258.36 \pm 31.83^{c}$ & $4.10 \pm 0.51^{b}$ \\
\hline$A$ & 24 h Dark & $8.01 \pm 0.90^{b c}$ & $23.62 \pm 0.21^{a}$ & $156.41 \pm 7.41^{d}$ & $2.76 \pm 0.34^{c}$ \\
\hline
\end{tabular}

Data are mean values from three biological replicate samples $\pm S D$. Values with the same letter within one organ are significantly different at $P<0.05$.

a step in the normal cytosolic glycolysis for energy metabolism, plastidal glycolysis using plastidal PFK contributes to starch breakdown and generation of metabolites for biosynthetic processes in dark-adapted or non-photosynthetic plastids (Plaxton, 1996). We propose that plastidal PFKs are light-dependently inactivated to avoid breakdown of photosynthates. But, we found significantly lower PFK activity in $24 \mathrm{~h}$ dark-incubated leaves and stems of rice plants exposed to ambient air (50\% activity in comparison to light-grown plants, Table 2). It is possible that the in vitro activity does not reflect the in planta activity which could be influenced by redox regulation and phosphorylation (Kachru and Anderson, 1975; Cséke et al., 1982; Heuer et al., 1982).

\section{PFK AND PFP GENE EXPRESSION UNDER ANOXIA}

The function of the two different phosphofructokinases in plants is still a matter of debate. It was hypothesized that plants might use PFP instead of PFK for the phosphorylation of fructose-6phosphate during ATP deficiency (Weiner et al., 1987; Mertens et al., 1990; Stitt, 1998). Our results show that anoxia-tolerant rice plants induce the expression of genes coding for both enzymes, PFK as well as PFP, during anoxia. OsPFK04 is a bona fide inducible gene upon anoxia in all organs, whereas OsPFK05 transcripts were moderately increased in stems and leaves (Figure 2). Induction of OsPFK04 transcript occurred within $30 \mathrm{~min}$ of anoxic stress. This rapid induction resembles that of accumulating PDC1 mRNA (Figure 2). It is suggested that rice has a sensitive and rapid signaling pathway for the detection of low-oxygen levels, most likely via post-translational and oxygen-dependent regulation of group VII
ERF transcription factors (Gibbs et al., 2011; Licausi et al., 2011). However, such induction of $P F K$ genes was also found for all other plant species observed (Figure 6), including low-oxygen-sensitive Arabidopsis (At4g26270, At4g32480) and soybean. Therefore, it can be proposed that induction of PFK is important for metabolism under oxygen deficiency in both, sensitive and tolerant plants.

Also OsPFPA3 and OsPFP-B transcripts were clearly increased in rice under anoxia in light and darkness (Figure 2), mainly in stems and leaves, which are the tissues with the highest tolerance to anoxia (Mustroph et al., 2006a,b). As stems and leaves store more carbohydrates and ferment them during anoxic periods, their cells survive anoxia better than root cells. Furthermore, these tissues might be able to produce more adaptive proteins, including PFP against stress through enhanced availability of photosynthetic energy. Interestingly, while PFPAs encoding the regulatory subunit were not induced in low-oxygen sensitive Arabidopsis or soybean plants, the OSPFPA3 was stronger induced in anoxic rice seedlings than the catalytic subunit $O s P F P-B$ (Figures 2 and 5) indicating a high importance for modulation of enzyme activity under oxygen deficiency (Figure 5). These results favor the idea that PFP plays a role in the reorganization of metabolism during low-oxygen stress in anoxia-tolerant leaves, but not in sensitive Arabidopsis plants or rice roots. However, the particular role of PFP in plant metabolism remains open. This question should be addressed in transgenic rice plants displaying reduced PFP activity.

Transcripts of four $P F K$ genes were found to be less abundant during anoxia compared to aeration (OsPFK06, OsPFK07, OsPFK08, OsPFK10; Figure 2). Remarkably, three of the four 
PFK genes are plastidic and belong to group PFK_C (Table 1). Also Arabidopsis, soybean and poplar PFK_C members were not induced under oxygen deficiency stress and hypothetically hint at reduced plastidal starch degradation and biosynthetic processes under oxygen deficiency. However, rice seeds are able to germinate under anoxia by making use of the amylase-degraded starch (Guglielminetti et al., 1995; Perata et al., 1997). It is not entirely excluded that either the degradation products of starch are translocated from plastids as hexoses, or plastidal PFK activity is mainly post-translationally stimulated despite the transcriptional reduction. Thus, more detailed studies are needed to elucidate the link between reduced OsPFK transcription of plastidlocalized isoforms and the response and adaptation to anoxic stress.

Illumination during the anoxic period greatly enhances the plant survival rates due to photosynthesis-driven ATP production (Mustroph et al., 2006b). In our recent analysis, we did not find dramatic differences in the induction of phosphofructokinase genes (Figure 2) or enzyme activities (Table 2) in light versus dark anoxia. This suggests that phosphofructokinase activity has not a major role in the positive effect of illumination during oxygen deficiency stress. But, all phosphofructokinase genes with reduced expression during an anoxic stress period showed an even stronger decrease in darkness than in light, especially in stems and leaves (Figure 2) suggesting an energy-dependent decrease of transcription in anoxia. It is reasonable to speculate on the avoidance of unwanted transcription and translation to save valuable ATP. It is reported that the highly energy-consuming translation of house-keeping genes is especially tightly regulated under oxygen deficiency stress (Branco-Price et al., 2008; Mustroph et al., 2009). In consistency, $\mathrm{ADH}$ and PDC activities did not increase as much during anoxia in darkness as in light (Table 2; Mustroph et al., 2006a,b).

Complete analyses of the expression of phosphofructokinase gene family under oxygen deficiency are only now possible after the identification of the entire gene family in rice. Previously, the effect of oxygen deficiency on the content of a single phosphofructokinase transcript was studied by RNA blot analysis in rice (Umeda and Uchimiya, 1994; Minhas and Grover, 1999). Based on our classification of the phosphofructokinase genes, both research groups monitored OsPFP-B and concluded that the transcript level is strongly increased upon oxygen deprivation. This is in agreement with our results showing a two- to threefold increase in the $O s P F P-B$ mRNA content (Figure 2). Data from recent microarray analyses using rice coleoptiles exposed to anoxic stress (LasanthiKudahettige et al., 2007; Narsai et al., 2009), and of rice leaves to submergence (Mustroph et al., 2010) confirmed the highest accumulation of OsPFK04 and OsPFK05 transcript levels among the phosphofructokinase genes (Figure 6; Table S3 in Supplementary Material). The microarray data also show a moderate induction of $O s P F P A 3$ and $O s P F P-B$ (Figure 5), as shown in our experiments (Figure 2). Furthermore, the reduced accumulation of OsPFK06, OsPFK08, OsPFK10, and OsPFPA1 transcripts during anoxia in comparison to the aerated controls was congruently presented in the microarray profiles and our studies. When expression patterns, for example from OsPFK01 and OsPFPA4, differ between reported and our own studies, these differences likely refer to the use of different plant tissues and rice cultivars as well as different growth conditions and stress applications.

\section{INDUCED EXPRESSION OF PHOSPHOFRUCTOKINASE GENES DOES MODIFY ENZYME ACTIVITIES ONLY SLIGHTLY}

Despite the fact that some PFK and PFP genes were strongly expressed during anoxia in rice compared to aeration, the activities of PFK and PFP in cell extracts were only slightly increased in response to anoxic treatment (Table 2). PFP activity increased slightly but not significantly after $24 \mathrm{~h}$ of anoxia in leaves, which correlated with increased OsPFPA3 transcript levels, while PFK activity was slightly induced in stems during illuminated anoxia. Although the translational activity of single mRNAs and the stability of individual isoforms are not known, it is proposed that the simultaneous increase of transcript amounts for two $P F K$ and two $P F P$ genes and the decrease of transcript amounts for four $P F K$ and three PFP genes contribute to the maintenance of the activity of both enzymes during anoxia (Figure 2). However, rice shoots, the most tolerant tissue in this study, showed an increase in PFP enzyme activity during long-term anoxia. This elevated activity was never obtained for the anoxia-sensitive Arabidopsis plants (data not shown) and could presumably partly contribute to anoxia tolerance.

Increased activities of PFP, but not of PFK were reported for rice coleoptiles (Mertens et al., 1990; Kato-Noguchi, 2002) or suspension cells (Mohanty et al., 1993) in response to oxygen deficiency. Two reasons could explain the lower activation of enzyme activity in the present experiments. First, plant organs respond differently to oxygen deficiency stress. Coleoptiles possess the highest anoxia tolerance among the different plant tissues and can survive several days of anoxia. Therefore, it is possible that among other factors this tolerance is due to strong increase of PFP activity. Second, the experimental conditions differ in the studies. Rice suspension cells were exposed to 12 and $24 \mathrm{~h}$ of anoxia in darkness with carbohydrate addition, and a sixfold PFP activity increase was determined, but no increase of PFK activity (Mohanty et al., 1993). Without additional sugar supply, dark-incubated rice seedlings do not tolerate anoxia for more than $24 \mathrm{~h}$ before they die (Mustroph et al., 2006a). It is likely that the sugar supplement enables the strong increase in enzyme activity in the previous study (Mohanty et al., 1993).

We conclude that, although the overall in vitro activity of PFK and PFP was only slightly modified during anoxic treatment, the induction and repression of several of the PFK and PFP genes contributes to changes of the in planta metabolic activity. The encoded phosphofructokinases could have different affinities to substrates and cofactors, such as fructose-6-phosphate, ATP, and PPi. Furthermore, PFK and PFP activities are highly regulated by other metabolites like magnesium or phosphoenolpyruvate (summarized in Plaxton, 1996). Another possible factor is phosphate, a potent activator of cytosolic PFK activity that functions as an inhibitor of plastidic PFK activity (Kelly and Latzko, 1977). In conclusion, the distinct upregulation of $P F P$ genes during anoxia in rice provides a means for the use of PPi instead of ATP for the conversion of fructose-6-P to fructose-1,6-BP. An increase in $P F P$ transcript levels and PFP activity during anoxia in rice likely alleviates the energy crisis. These regulatory mechanisms were 
not observed in low-oxygen sensitive plants, such as Arabidopsis, soybean, or poplar.

\section{ACKNOWLEDGMENTS}

We thank Dr. Gynheung An and Elena Iulia Boamfa for providing us with rice seeds. Dr. Julia Bailey-Serres is acknowledged for helpful discussion and editing of an earlier version of the manuscript. We thank Christina Kühn and Markus Hermann for technical support at the confocal microscope.

\section{SUPPLEMENTARY MATERIAL}

The Supplementary Material for this article can be found online at http://www.frontiersin.org/Plant_Physiology/10.3389/ fpls.2013.00125/abstract

Figure S1 | Alignment of amino acid sequences of PFKs from Arabidopsis and rice. The sequences were aligned by use of the ClustalW method (http://www.genome.jp/tools-bin/clustalw). Similar amino acids are marked with shadows. The letters $A, B$, and $C$ mark the three PFK subgroups. For the alignment, the corrected protein sequences for LOC_Os08g34050 (OsPFK07) and LOC_Os09g24910 (OsPFK08) were used (see Figure S2 in Supplementary Material)

Figure S2 | Modified nucleotide and protein sequences for LOC_Os08g34050 (OsPFK07), LOC_Os09g24910 (OsPFK08), and LOC_Os09g12650 (OsPFPA4) after sequencing of several PCR products and comparison to the annotated sequences. For OSPFK07, two versions were

\section{REFERENCES}

Albrecht, G., Mustroph, A., and Fox, T. C. (2004). Sugar and fructan accumulation during metabolic adjustment between respiration and fermentation under low oxygen conditions in wheat roots. Physiol. Plant 120, 93-105.

Bailey-Serres, J., and Voesenek, L. A. C. J. (2008). Flooding stress: acclimations and genetic diversity. Annu. Rev. Plant Biol. 59, 313-339.

Bayley, C. C., Morgan, M., Dale, E. C., and Ow, D. W. (1992). Exchange of gene activity in transgenic plants catalyzed by the Cre-lox site-specific recombination system. Plant Mol. Biol. 18, 353-361.

Bendahmane, A., Querci, M., Kanyuka, K., and Baulcombe, D. C. (2000). Agrobacterium transient expression system as a tool for the isolation of disease resistance genes: application to the $\mathrm{Rx} 2$ locus in potato. Plant J. 21, 73-81.

Biemelt, S., Hajirezaei, M. R., Melzer, M., Albrecht, G., and Sonnewald, U. (1999). Sucrose synthase activity does not restrict glycolysis in roots of transgenic potato plants under hypoxic conditions. Planta 210, 41-49.

Bouny, J. M., and Saglio, P. H. (1996). Glycolytic flux and hexokinase activities in anoxic maize root tips acclimated by hypoxic pre-treatment. Plant Physiol. 111, 187-197.
Bradford, M. M. (1976). A rapid and sensitive method for the quantification of microgram quantities of protein utilizing the principle of protein-dye binding. Anal. Biochem. 72, 248-254.

Branco-Price, C., Kaiser, K. A., Jang, C. J., Larive, C. K., and Bailey-Serres, J. (2008). Selective mRNA translation coordinates energetic and metabolic adjustments to cellular oxygen deprivation and reoxygenation in Arabidopsis thaliana. Plant J. 56, 743-755.

Carlisle, S. M., Blakeley, S. D., Hemmingsem, S. M., Trevanion, S. J., Hiyoshi, T., Kruger, N. J., et al. (1990). Pyrophosphate-dependent phosphofructokinase. Conservation of protein sequence between the alpha- and beta- subunits and with the ATP-dependent phosphofructokinase. J. Biol. Chem. 265, 18366-18371.

Cawood, M. C., Botha, F. C., and Small, J. G. C. (1988). Properties of the phosphofructokinase isoenzymes from germinating cucumber seeds. J. Plant Physiol. 132, 204-209.

Christianson, J. A., Llewellyn, D. J., Dennis, E. S., and Wilson, I. W. (2010). Global gene expression responses to waterlogging in roots and leaves of cotton (Gossypium hirsutum L.). Plant Cell Physiol. 51, 21-37.

Cséke, C., Nishizawa, A. N., and Buchanan, B. B. (1982). Modulation

found in different varieties, one for Nipponbare (as well as Cigalon, M202, Dongjin, Hwayoung), and one for FR13A (as well as CT6241).

Figure S3 | Subcellular localization of PFK isoforms from rice. Full-length mRNA sequences or the $\mathrm{N}$-terminal part of the sequences were cloned in frame in front of a GFP-coding sequence and were transiently transformed into tobacco leaves by Agrobacterium infiltration. After 3-4 days, protoplasts or undigested leaf disks were isolated and analyzed by confocal microscopy. Green color represents GFP fluorescence, red color represents chlorophyll autofluorescence. Full-length CDS: (A) OsPFK01; (B) OsPFK02; (C) OsPFK04 (D) OsPFK05; (E) OsPFK06; (I,J) OsPFK03; (O) OsPFK09; (S) OsPFK08; (T) OsPFK10. N-terminal part: (F-H) OsPFK03; (K-N) OsPFK09; (P-R) OsPFK05.

Figure S4 | Expression of the PFK_B group members in different organs. eFP browser pictures were obtained through http://bar.utoronto.ca Winter et al., 2007). Red color intensity shows high expression level in the respective tissue type.

Table S1 | Primers used for the experiments. Actin primers were those used by Ren et al. (2005).

Table S2 | Semi-quantitative RT-PCR analysis of rice phosphofructokinase genes: conditions for the PCR reactions.

Table S3 | Data for differential gene expression of phosphofructokinase genes in rice under oxygen-deficient conditions, obtained by microarray analyses with the Affymetrix rice Microarray Chip (Lasanthi-Kudahettige et al., 2007; Narsai et al., 2009; Mustroph et al., 2010). The signal-log-ratio (SLR) of all probe-sets is shown for each sample set. Data had been analyzed previously by GC-RMA.

of chloroplast phosphofructokinase by NADPH: a mechanism for linking light to the regulation of glycolysis. Plant Physiol. 703, 658-661.

Dancer, J. E., and ap Rees, T. (1989). Effects of 2,4-dinitrophenol and anoxia on the inorganic pyrophosphate content of the spadix of Arum maculatum and the root apices of Pisum sativum. Planta 178, 421-424.

Dereeper, A., Guignon, V., Blanc, G., Audic, S., Buffet, S., Chevenet, F., et al. (2008). Phylogeny.fr: robust phylogenetic analysis for the nonspecialist. Nucleic Acids Res. 36, W465-W469.

de Sousa, C. A. F., and Sodek, L. (2002). The metabolic response of plants to oxygen deficiency. Braz. J. Plant Physiol. 14, 83-94.

Drew, M. C. (1997). Oxygen deficiency and root metabolism: injury and acclimation under hypoxia and anoxia. Annu. Rev. Plant Physiol. Plant Mol. Biol. 48, 223-250.

Earley, K., Haag, J. R., Pontes, O., Opper, K., Juehne, T., Keming, S., et al. (2006). Gateway-compatible vectors for plant functional genomics and proteomics. Plant J. 45, 616-629.

Emanuelsson, O., Nielsen, H., Brunak, S., and von Heijne, G. (2000). Predicting subcellular localization of proteins based on their N-terminal amino acid sequence. J. Mol. Biol. 300, 1005-1016.
Geigenberger, P. (2003). Response of plant metabolism to too little oxygen. Curr. Opin. Plant Biol. 6, 247-256.

Gibbs, D. J., Lee, S. C., Isa, N., Gramuglia, S., Fukao, T., Bassel, G. W., et al. (2011). Homeostatic response to hypoxia is regulated by the $\mathrm{N}$-end rule pathway in plants. Nature 479 , 415-418.

Gibbs, J., and Greenway, H. (2003). Mechanisms of anoxia tolerance in plants. I. Growth, survival and anaerobic catabolism. Funct. Plant Biol. 30, 1-47.

Gibbs, J., Morrell, S., Valdez, A., Setter, T. L., and Greenway, H. (2000). Regulation of alcoholic fermentation in coleoptiles of two rice cultivars differing in tolerance to anoxia. J. Exp. Bot. 51, 785-796.

Gibon, Y., Blaesing, O. E., Hannemann, J., Carillo, P., Höhne, M., Hendriks, J. H. M., et al. (2004). A robot-based platform to measure multiple enzyme activities in Arabidopsis using a set of cycling assays: comparison of changes of enzyme activities and transcript levels during diurnal cycles and in prolonged darkness. Plant Cell 16, 3304-3325.

Guglielminetti, L., Perata, P., and Alpi, A. (1995). Effect of anoxia on carbohydrate metabolism in rice seedlings. Plant Physiol. 108, 735-741. 
Hajirezaei, M. R., Sonnewald, U., Viola, R., Carlise, S., Dennis, D., and Stitt, M. (1994). Transgenic potato plants with strongly decreased expression of pyrophosphate:fructose-6phosphate phosphotransferase show no visible phenotype and only minor changes in metabolic fluxes in their tubers. Planta 192, 16-33.

Heuer, B., Hansen, M. J., and Anderson, L. E. (1982). Light modulation of phosphofructokinase in pea leaf chloroplasts. Plant Physiol. 69, 1404-1406.

Horton, P., Park, K.-J., Obayashi, T., and Nakai, K. (2006). "Protein subcellular localization prediction with WoLF PSORT," in Proceedings of Asian Pacific Bioinformatics Conference 2006, Taipei.

Hsu, F. C., Chou, M. Y., Peng, H. P., Chou, S. J., and Shih, M. C. (2011). Insights into hypoxic systemic responses based on analyses of transcriptional regulation in Arabidopsis. PLoS ONE 6:e28888. doi:10.1371/journal.pone.0028888

Huang, S., Colmer, T. D., and Millar, A. H. (2008). Does anoxia tolerance involve altering the energy currency towards PPi? Trends Plant Sci. 13, 221-227.

Kachru, R. B., and Anderson, L. E. (1975). Inactivation of pea leaf phosphofructokinase by light and dithiothreitol. Plant Physiol. 55, 199-202.

Kapri, R., Dahan, E., Zehavi, U., Goren, R., and Sadka, A. (2000). Cloning and characterization of PPi-phosphofructokinase from citrus fruit. Acta Hortic. 535, 113-118.

Karimi, M., Inze, D., and Depicker, A. (2002). Gateway vectors for Agrobacterium-mediated plant transformation. Trends Plant Sci. 7, 193-195.

Kato-Noguchi, H. (2002). The catalytic direction of pyrophosphate:fructose 6-phosphate 1-phosphotransferase in rice coleoptiles in anoxia. Physiol. Plant 116, 345-350.

Kelly, G. J., and Latzko, E. (1977). Chloroplast phosphofructokinase. II. Partial purification, kinetic and regulatory properties. Plant Physiol. 60, 295-299.

Knowles, V. L., Greyson, M. F., and Dennis, D. T. (1990). Characterization of ATP-dependent fructose 6-phosphate 1-phosphotransferase isozymes from leaf and endosperm tissues of Ricinus communis. Plant Physiol. 92, 155-159.

Kreuzwieser, J., Hauberg, J., Howell, K. A., Carroll, A., Rennenberg, H., Millar, A. H., et al. (2009). Differential response of gray poplar leaves and roots underpins stress adaptation during hypoxia. Plant Physiol. $149,461-473$.

Lasanthi-Kudahettige, R., Magneschi, L., Loreti, E., Gonzali, S., Licausi, F., Novi, G., et al. (2007). Transcript profiling of the anoxic rice coleoptile. Plant Physiol. 144, 218-231.

Lee, S. C., Mustroph, A., Sasidharan, R., Vashisht, D., Pedersen, O., Oosumi, T., et al. (2011). Molecular characterization of the submergence response of the Arabidopsis thaliana ecotype Columbia. New Phytol. 190, 457-471.

Licausi, F., Kosmacz, M., Weits, D. A., Giuntoli, B., Giorgi, F. M., Voesenek, L. A. C. J., et al. (2011). Oxygen sensing in plants is mediated by an $\mathrm{N}$-end rule pathway for protein destabilization. Nature 479, 419-422.

Mertens, E., Laroundelle, Y., and Hers, H.-G. (1990). Induction of pyrophosphate:fructose 6phosphate 1-phosphotransferase by anoxia in rice seedlings. Plant Physiol. 93, 584-587.

Minhas, D., and Grover, A. (1999). Transcript levels of genes encoding various glycolytic and fermentation enzymes change in response to abiotic stresses. Plant Sci. 146, 41-51.

Mohanty, B., Wilson, P. M., and ap Rees, T. (1993). Effects of anoxia on growth and carbohydrate metabolism in suspension cultures of soybean and rice. Phytochemistry 34, 75-82.

Mustroph, A., and Albrecht, G. (2003). Tolerance of crop plants to oxygen deficiency stress: fermentative activity and photosynthetic capacity of entire seedlings under hypoxia and anoxia. Physiol. Plant 117, 508-520.

Mustroph, A., Albrecht, G., Hajirezaei, M. R., Grimm, B., and Biemelt, S. (2005). Low levels of pyrophosphate in transgenic potato plants expressing $E$. coli pyrophosphatase lead to decreased vitality under oxygen deficiency. Ann. Bot. 96, 717-726.

Mustroph, A., Boamfa, E. I., Laarhoven, L. J. J., Harren, F. J. M., Albrecht, G., and Grimm, B. (2006a). Organ specific analysis of the anaerobic primary metabolism in rice and wheat seedlings I: dark ethanol production is dominated by the shoots. Planta 225, 103-114.

Mustroph, A., Boamfa, E. I., Laarhoven, L. J. J., Harren, F. J. M., Pörs, Y., and Grimm, B. (2006b). Organ specific analysis of the anaerobic primary metabolism in rice and wheat seedlings II: light exposure reduces needs for fermentation and extends survival during anaerobiosis. Planta 225, 139-152.
Mustroph, A., Lee, S. C., Oosumi, T., Zanetti, M. E., Yang, H., Ma, K., et al. (2010). Cross-kingdom comparison of transcriptomic adjustments to low-oxygen stress highlights conserved and plant-specific responses. Plant Physiol. 152, 1484-1500.

Mustroph, A., Sonnewald, U., and Biemelt, S. (2007). Characterisation of the ATP-dependent phosphofructokinase gene family from Arabidopsis thaliana. FEBS Lett. 581, 2401-2410.

Mustroph, A., Zanetti, M. E., Jang, C. J., Holtan, H. E., Repetti, P. P., Galbraith, D. W., et al. (2009). Profiling translatomes of discrete cell populations resolves altered cellular priorities during hypoxia in Arabidopsis. Proc. Natl. Acad. Sci. U.S.A. 106 , 18843-18848

Nanjo, Y., Maruyama, K., Yasue, H., Yamaguchi-Shinozaki, K., Shinozaki, K., and Komatsu, S. (2011). Transcriptional responses to flooding stress in roots including hypocotyl of soybean seedlings. Plant Mol. Biol. $77,129-144$.

Narsai, R., Howell, K. A., Carroll, A., Ivanova, A., Millar, A. H. and Whelan, J. (2009). Defining core metabolic and transcriptomic responses to oxygen availability in rice embryos and young seedlings. Plant Physiol. 151, 306-322.

Nielsen, T. H., Rung, J. H., and Villadsen, D. (2004). Fructose-2,6bisphosphate: a traffic signal in plant metabolism. Trends Plant Sci. 9, 556-563.

Ouyang, S., Zhu, W., Hamilton, J., Lin, H., Campbell, M., Childs, K., et al. (2007). The TIGR rice genome annotation resource: improvements and new features. Nucleic Acids Res. 35, D883-D887.

Perata, P., Guglielminetti, L., and Alpi, A. (1996). Anaerobic carbohydrate metabolism in wheat and barley, two anoxia-intolerant cereal seeds. $J$. Exp. Bot. 47, 999-1006.

Perata, P., Guglielminetti, L., and Alpi, A. (1997). Mobilization of endosperm reserves in cereal seeds under anoxia. Ann. Bot. 79, 40-56.

Plaxton, W. C. (1996). The organization and regulation of plant glycolysis. Annu. Rev. Plant Physiol. Plant Mol. Biol. 48, 185-214.

Ren, Z. H., Gao, J. P., Li, L. G., Cai, X. L., Huang, W., Chao, D. Y., et al. (2005). A rice quantitative trait locus for salt tolerance encodes a sodium transporter. Nat. Genet. 37, 1141-1146.

Ricard, B., Rivoal, J., Spiteri, A., and Pradet, A. (1991). Anaerobic stress induces the transcription of sucrose synthase in rice. Plant Physiol. 95, 669-674.

Ricard, B., Van Toai, T., Chourey, P., and Saglio, P. (1998). Evidence for the critical role of sucrose synthase for anoxic tolerance of maize roots using a double mutant. Plant Physiol. 116, 1323-1331.

Saeed, A. I., Bhagabati, N. K., Braisted, J. C., Liang, W., Sharov, V., Howe, E. A., et al. (2006). TM4 microarray software suite. Meth. Enzymol. 411, 134-193.

Springer, B., Werr, W., Starlinger, P., Bennet, D. C., Zokolica, M., and Freeling, M. (1986). The shrunken gene on chromosome 9 of Zea mays L. is expressed in various plant tissues and encodes an anaerobic protein. Mol. Gen. Genet. 205, 461-468.

Stitt, M. (1998). Pyrophosphate as an energy donor in the cytosol of plant cells: an enigmatic alternative to ATP. Bot. Acta 111, 167-175.

Summers, J. E., Ratcliff, R. G., and Jackson, M. B. (2000). Anoxia tolerance in the aquatic monocot Potamogeton pectinatus: absence of oxygen stimulates elongation in association with an unusually large Pasteur effect. $J$. Exp. Bot. 51, 1413-1422.

Suzuki, J., Mutton, M. A., Ferro, M. I. T., Lemos, M. V. F., Pizauro, F. M., Mutton, M. J. R., et al. (2003). Putative pyrophosphate phosphofructose 1-kinase genes identified in sugar cane may be getting energy from pyrophosphate. Genet. Mol. Res. 2, 376-382.

Teramoto, M., Koshiishi, C., and Ashihara, H. (2000) Wound-induced respiration and pyrophosphate:fructose-6phosphate phosphotransferase in potato tubers. Z. Naturforsch. C 55, 953-956.

Theodorou, M. E., Cornel, F. A., Duff, S. M., and Plaxton, W. C. (1992). Phosphate starvationinducible synthesis of the alphasubunit of the pyrophosphatedependent phosphofructokinase in black mustard suspension cells. J. Biol. Chem. 267, 21901-21905.

Theodorou, M. E., and Plaxton, W. C. (1996). Purification and characterization of pyrophosphatedependent phosphofructokinase from phosphate-starved Brassica nigra suspension cells. Plant Physiol. $112,343-351$

Todd, J. F., Blakeley, S. D., and Dennis, D. T. (1995). Structure of the genes encoding the alpha- and beta-subunits of castor pyrophosphate-dependent phosphofructokinase. Gene 152, 181-186. 
Turner, W. L., and Plaxton, W. C. (2003). Purification and characterization of pyrophosphate- and ATP-dependent phosphofructokinases from banana fruit. Planta 217, 113-121.

Umeda, M., and Uchimiya, H. (1994). Differential transcript levels of genes associated with glycolysis and alcohol fermentation in rice plants (Oryza sativa L.) under submergence stress. Plant Physiol. 106, 1015-1022.

Waters, I., Morell, S., Greenway, H., and Colmer, D. (1991). Effects of anoxia on wheat seedlings. II Influence of $\mathrm{O} 2$ supply prior to anoxia on tolerance to anoxia, alcoholic fermentation, and sugar levels. J. Exp. Bot. 42, 1437-1447.

Weiner, H., Stitt, M., and Heldt, H. W. (1987). Subcellular compartmentation of pyrophosphate and alkaline pyrophosphatase in leaves. Biochim. Biophys. Acta 893, 13-21.

Winkler, C., Delvos, B., Martin, W., and Henze, K. (2007). Purification, microsequencing and cloning of spinach ATP-dependent phosphofructokinase link sequence and function for the plant enzyme. FEBS J. 274, 429-438.

Winter, D., Vinegar, B., Nahal, H. Ammar, R., Wilson, G. V., and Provart, N. J. (2007). An "electronic fluorescent pictograph" browser for exploring and analyzing large-scale biological data sets. PLoS ONE 2:e718. doi:10.1371/journal.pone.0000718

Wong, J. H., Kiss, F., Wu, M.-X., and Buchanan, B. B. (1990).
Pyrophosphate fructose-6-P 1phosphotransferase from tomato fruit. Evidence for change during ripening. Plant Physiol. 94, 499-506.

Yan, T. F. J., and Tao, M. (1984). Multiple forms of pyrophosphate-fructose6-phosphate 1-phosphotransferase from wheat seedlings. J. Biol. Chem. 259, 5087-5092.

Conflict of Interest Statement: The authors declare that the research was conducted in the absence of any commercial or financial relationships that could be construed as a potential conflict of interest.

Received: 22 February 2013; paper pending published: 18 March 2013; accepted: 17 April 2013; published online: 14 May 2013.
Citation: Mustroph A, Stock J, Hess $N$, Aldous S, Dreilich A and Grimm $B$ (2013) Characterization of the phosphofructokinase gene family in rice and its expression under oxygen deficiency stress. Front. Plant Sci. 4:125. doi: 10.3389/fpls.2013.00125

This article was submitted to Frontiers in Plant Physiology, a specialty of Frontiers in Plant Science.

Copyright (c) 2013 Mustroph, Stock, Hess, Aldous, Dreilich and Grimm. This is an open-access article distributed under the terms of the Creative Commons Attribution License, which permits use, distribution and reproduction in other forums, provided the original authors and source are credited and subject to any copyright notices concerning any third-party graphics etc. 